\title{
DIVERSIDAD ARTEFACTUAL VS. ESPECIALIZACIÓN FUNCIONAL. ANÁLISIS DEL IV COMPONENTE DE TÚNEL I (TIERRA DEL FUEGO, ARGENTINA)
}

\author{
MARÍA ESTELA MANSUR Y ADRIANA LASA ${ }^{1}$
}

\begin{abstract}
RESUMEN
El conjunto lítico del IV Componente de Túnel 1 comparte las características generales de los conjuntos de la región, pero presenta además otras singulares, entre ellas la inusualmente alta representación de raspadores (aproximadamente 95\% de los instrumentos), del cuarzo como materia prima (aproximadamente 86\% del total) y de utilización de técnica de talla bipolar (aproximadamente 12\% del total). Estas características sugieren una alta especialización tecnológica y funcional. Por tal motivo se decidió encarar un estudio integral de los materiales, que permitió poner en evidencia las interrelaciones entre los criterios de materia prima, técnica de manufactura y morfología de los artefactos, así como entre ellos y el uso de las piezas, acercándonos a una caracterización más fina de las actividades desarrolladas durante la ocupación. A partir de ellas, es posible inferir algunas de las estrategias tecnológicas implementadas, en el marco de prácticas sociales que implican procesos de toma de decisiones y de ejecución, que pueden ser abordadas desde el análisis del material lítico.
\end{abstract}

PALABRAS CLAVES: organización tecnológica, análisis funcional, rastros de uso, raspadores, cuarzo, bipolares.

\section{ARTIFACT DIVERSITY VS. FUNCTIONAL SPECIALIZATION ANALYSIS OF THE IV COMPONENT OF TÚNEL I (TIERRA DEL FUEGO, ARGENTINA)}

\begin{abstract}
The lithic assemblage of component IV of the Túnel 1 site broadly conforms to the general characteristics of other assemblages in the region. However, a host of singular features are also evident, including here an unusually high proportion of end scrapers (approximately 95\% of tools), a reliance on quartz as raw material (approximately $86 \%$ of the assemblage/all tools), and the use of a bipolar flaking technique (12\%). These features suggest a high degree of technical and functional specialization. An in-depth study of the assemblage shows interrelationships both between choices of raw material, manufacturing technique and tool morphology, as well as between the latter and tool use. The study has enabled a higher definition understanding of the activities that took place during the occupation of the site and, thereby, allowed inferences about both aspects of lithic technology strategies and their place in the sphere of social practices that implicate processes of decision-making and execution.
\end{abstract}

KEY WORDS: technological organization, functional analysis, microwear, endscapers, quartz, bipolars.

1 Laboratorio de Antropología, CADIC, 9410 Ushuaia, Tierra del Fuego, Argentina. E-mail: memansur@tierradelfuego.org.ar 


\section{INTRODUCCIÓN ${ }^{1}$}

El sitio Túnel I ocupa un punto céntrico en la localidad arqueológica homónima, ubicada sobre la costa norte del canal Beagle, a la que los indígenas de los últimos tiempos llamaban Hannaracush (Orquera y Piana 1999a). Por su ubicación sobre un espolón de la ladera, a unos $80 \mathrm{~m}$ de distancia de la costa actual, a unos $15 \mathrm{~m}$ sobre el nivel de mareas altas y próximo al bosque que cubre el faldeo meridional de la cordillera, el sitio cuenta con excelente visibilidad sobre la zona circundante y brinda acceso a una amplia variedad de recursos (Fig. 1). La estratigrafía está formada por una alternancia de capas de limo y de acumulaciones de conchal y en ella pudieron ser identificados seis componentes (Orquera y Piana 1988, 1999a).

El presente trabajo está consagrado al análisis de los materiales del IV Componente $e^{2}$. Este compren- de los materiales arqueológicos y arqueofaunísticos -y su contexto espacial y estructural- hallados en una pequeña serie de acumulaciones de conchal que ocupaban el cuadrante sudoeste de la porción excavada del sitio, denominados lentes $\alpha$ y X, como así también en la superficie de contacto superior de esas lentes con la superpuesta capa terrosa $\mathrm{C}^{3}$.

El componente mencionado comparte, en líneas generales, las características de los otros conjuntos de la región ("Tradición adaptativa de los canales Magallánico-fueguinos", sensu Orquera y Piana 1988, 1999a). Sin embargo presenta también una serie de rasgos totalmente singulares, entre los cuales resaltan la alta representación de raspadores (aproximadamente 95\% de los instrumentos), el cuarzo como materia prima (aproximadamente $86 \%$ del total) y de utilización de técnica de talla bipolar (aproximadamente 12\% del total), así como la baja representación de raederas (aprox. 4\% de

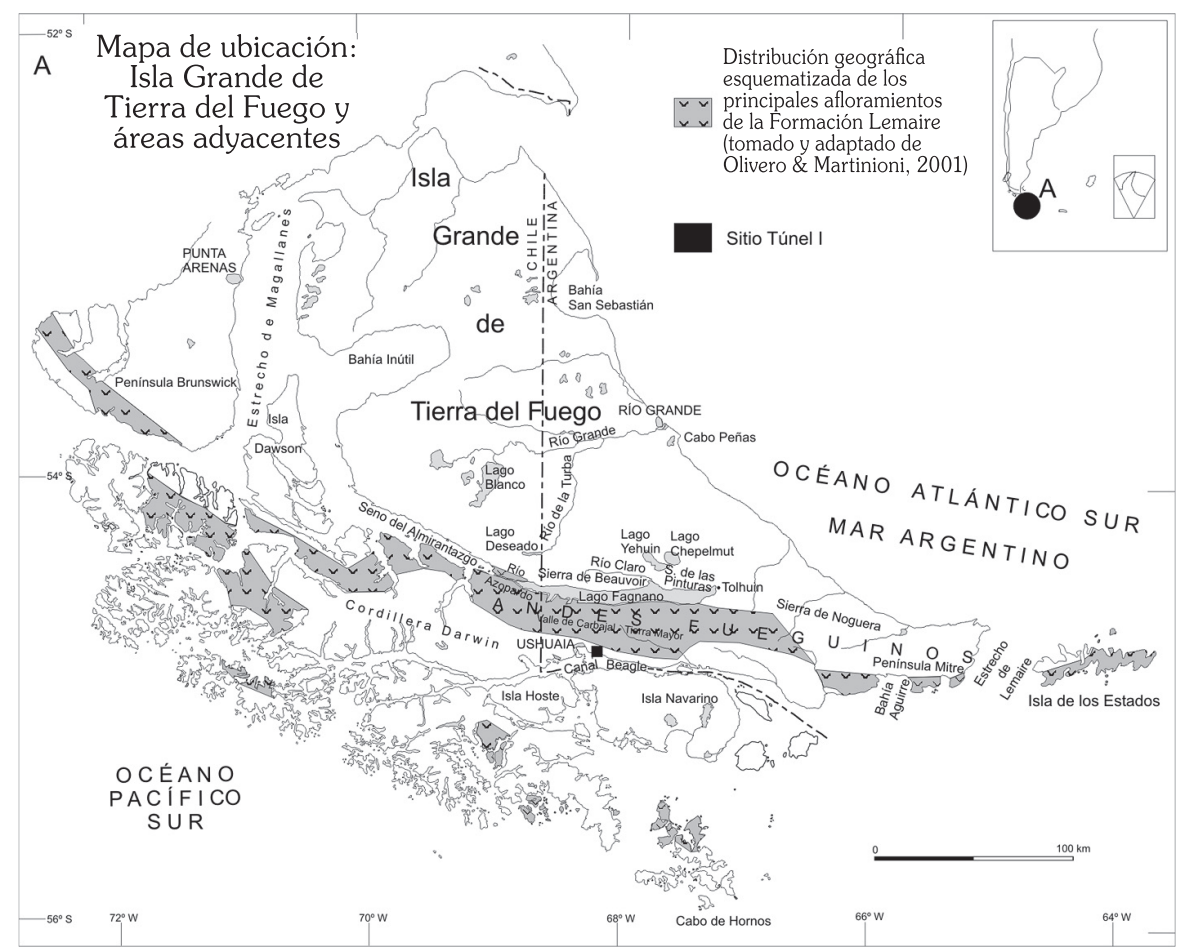

Fig. 1. Mapa de Tierra del Fuego.

1 Un trabajo preliminar sobre el análisis de los materiales del IV Componente, que enfatiza en algunos aspectos de la relación tecnología-función, fue presentado en el Simposio "Perspectivas en el análisis de conjuntos líticos - Teoría, metodología y nuevas tendencias", realizado en el XV Congreso Nacional de Arqueología Argentina.

2 Esta expresión debe ser entendida en el sentido dado en Orquera y Piana 1999a: nota 30.
3 En la porción superior de la delgada capa C1, en contacto con la superpuesta lente, aparecieron unos pocos restos líticos morfológicamente similares a los incluidos en el Cuarto Componente, asociados a algunos restos de fauna. Como no es posible determinar si se trata de una redepositación con asociaciones aleatorias o de una reocupación del sitio con características similares a las del Cuarto Componente, esos materiales no han sido incluidos en este estudio. 


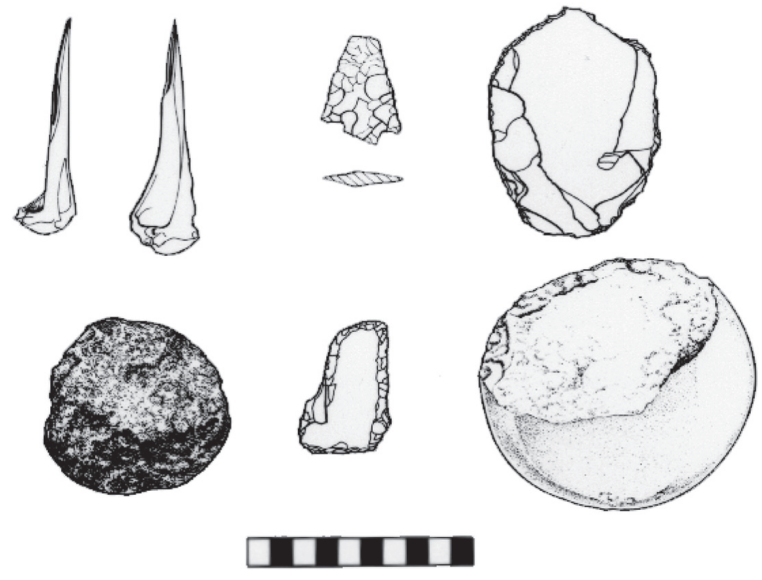

Fig. 2. Materiales del IV Componente.

los instrumentos), de lascas con filos naturales con esquirlamiento (hay sólo 7), de puntas de proyectil (sólo una) y de instrumental óseo (Fig. 2).

Por su bajo índice de diversidad artefactual, calculada según el índice de Shannon y Weaver (1949), el conjunto del IV Componente ha sido considerado como uno de los que ilustran el patrón general de los cazadores-recolectores del Canal Beagle (Lanata 2000). Según J. L. Lanata, la mayor posibilidad de palimpsesto regional en esta zona podría ser la causa de los índices altos de diversidad artefactual, sin tener que pensar forzosamente en una diversificación tecnológica o artefactual; al contrario, muestras con bajos índices son consideradas como el patrón general. Sin embargo, la característica esencial del IV Componente, más allá de la baja diversidad artefactual, es el hecho que la mayor parte de los instrumentos pertenecen a un tipo, el de los raspadores, que está comparativamente mal representado en los otros conjuntos de la región. A su frecuencia abrumadora y su casi exclusiva correlación con una única materia prima, el cuarzo, los raspadores del IV Componente agregan como dato de interés su muy alto grado de concentración espacial, ya que más del 70\% de los raspadores fueron descubiertos en una superficie de aproximadamente $4 \mathrm{~m}^{2}$. Las razones que provocaron una tan grande concentración de raspadores y la estricta selección de un material tan poco apto para la talla como el cuarzo, características inusuales en los componentes de este y otros sitios de la región, podrían ser de índole funcional.
En la literatura arqueológica, los raspadores han sido tradicionalmente asociados al trabajo de pieles. Ello deriva ante todo de la comparación con múltiples ejemplos etnográficos que han mostrado su coherencia como instrumentos específicamente destinados a esta actividad, así como de los análisis funcionales de base microscópica realizados a numerosas colecciones arqueológicas, que arrojaron el mismo resultado. Sin embargo, en el caso del IV Componente de Túnel I, se nos plantearon dos objeciones importantes. La primera es que el número de raspadores supera mucho a lo que se supondría necesario para raspar la cantidad de cueros deducible de los restos arqueofaunísticos aparecidos en las mismas capas (ver más abajo). La segunda, que ni las fuentes escritas ni los resultados del análisis funcional de materiales de otras ocupaciones del Canal acordaban relevancia al uso de tales instrumentos para el trabajo de pieles, por lo cual se había sugerido que su uso había sido reemplazado por el de los cuchillos y cinceles de valva (Orquera y Piana 1999b; Mansur y Vila, 1993; Mansur y Clemente, 2002).

Por estos motivos, al comenzar este estudio nos planteamos una hipótesis alternativa: que los raspadores del IV Componente podían haber sido utilizados para la preparación de algún otro tipo de material y que las otras categorías de instrumentos asociados podían igualmente estar vinculadas con tal actividad. Sin embargo, los resultados de un análisis preliminar de los raspadores y su comparación con otros conjuntos de la zona del canal Beagle (Álvarez et al., 2000) nos llevaron a rechazar la hipótesis propuesta y confirmaron la importancia de encarar un estudio integral que permitiese evaluar las interrelaciones entre los criterios de materia prima, técnica de manufactura y morfología de los artefactos, así como entre ellos y el uso de las piezas, acercándonos a una caracterización más fina de las actividades desarrolladas durante la ocupación y en general de la organización tecnológica del IV Componente.

\section{EL IV COMPONENTE: MATERIALES E HIPÓTESIS}

En comparación con otros de la región, los conjuntos artefactuales lítico y óseo del IV Componente son relativamente escasos y se caracterizan por su baja diversidad. En el caso del material lítico, éste está constituido por 2723 artefactos. Entre ellos, 
Tabla 1. Material lítico del IV Componente.

\begin{tabular}{|l|c|c|c|c|c|c|c|c|c|c|c|c|c|}
\hline \multicolumn{10}{|c|}{ MATERIAL LÍTICO DEL IV COMPONENTE } \\
\hline & BAS & ESQ & HOR & ANF & AR & CI & LU & ND & PIZ & QZ & RIO & SI & total \\
\hline Instr. Retocados & & 1 & & & & 4 & 1 & & 1 & 136 & 3 & 1 & 147 \\
\hline Instr. Puliment. & 1 & & 1 & & & & & & & & & & 2 \\
\hline Percutores & & & & & & & & & & 1 & & & 1 \\
\hline Núcleos & & & & 0 & 0 & 0 & 1 & 0 & 0 & 5 & 1 & 0 & 7 \\
\hline Restos de talla & & & & 1 & 1 & 179 & 44 & 0 & 36 & 2196 & 96 & 4 & 2557 \\
\hline Lascas CESFN & & & & 0 & 0 & 0 & 1 & 1 & 3 & 0 & 2 & 0 & 7 \\
\hline Guijarros & & & & 0 & 0 & 0 & 0 & 0 & 0 & 0 & 2 & 0 & 2 \\
\hline TOTALES & 1 & 1 & 1 & 1 & 1 & 183 & 47 & 1 & 40 & 2338 & 104 & 5 & 2723 \\
\hline Porcentajes & 0,04 & 0,04 & 0,04 & 0,04 & 0,04 & 6,72 & 1,73 & 0,04 & 1,47 & 85,86 & 3,82 & 0,18 & 100,00 \\
\hline
\end{tabular}

BAS: basalto. ESQ: esquisto. HOR: hornblendita. ANF: anfibolita. AR: arcilita.

CI: cinerita. LU: lutita. ND: no determinable. PIZ: pizarra. QZ: cuarzo. RIO: riolita. SI: sílice.

las piezas retocadas comprenden 140 raspadores, 6 raederas y una punta bifacial ${ }^{4}$. Hay además un guijarro con superficie piqueteada, uno con cara pulimentada y un percutor. Entre los restos de talla, 2557 son piezas no retocadas y 7 son fragmentos correspondientes a 6 núcleos. Fueron reconocidas además 7 lascas con filos naturales con esquirlamiento (Tabla 1).

El instrumental óseo está exclusivamente representado por 4 punzones huecos (dos enteros, uno fragmentado y un fragmento), 3 cuentas de collar confeccionadas en valva y una en hueso de ave, un fragmento de metapodio de guanaco con el canal externo anterior ensanchado y una punta de arpón fragmentada (Tabla 2).

En cuanto a la fauna, se hallaron 1460 especímenes correspondientes a guanacos, 658 a pinnípedos, 23 a cetáceos, 960 a aves, 54 a peces y dos a un cánido no determinado. Los especímenes de guanacos representan a 9 individuos, todos

4 La cantidad de raspadores es ligeramente superior a la indicada en publicaciones anteriores (por ejemplo Orquera y Piana 1988, 1999a; Álvarez et al., 2000, donde figuraban 116), porque el análisis microscópico permitió incluir piezas que macroscópicamente no eran evidentes o resultaban dudosas. adultos o juveniles de tamaño grande, en tanto que los de pinnípedos representan a 10 individuos de tamaños diversos. Los de cetáceos corresponderían a dos diferentes delfínidos.

Con respecto a la estacionalidad, algunos cortes de caninos superiores de pinnípedos realizados por A. Schiavini sugieren que la ocupación se habría producido a fines del invierno o comienzos de la primavera. Ello no es suficiente para afirmar que toda la lente se formó en esa única época del año, aunque observaciones estratigráficas sugieren que el lapso de formación habría sido muy breve (Orquera y Piana, 1999a). Dos fechados radiocarbónicos la ubican en hace alrededor de 2700 años: $2660 \mathrm{AP}$ \pm 100 (AC 1030) y $2690 \mathrm{AP} \pm 80$ (Beta 2516)

En cuanto a la funcionalidad de la ocupación, la singularidad del conjunto instrumental, sumada al breve lapso estimado para su formación, llevaron a considerar la hipótesis de que se tratase de un campamento de función especializada, en cuyo transcurso se hubiese desarrollado algún tipo de actividad predominante. Su ubicación estacional

5 Hay un tercer fechado que no difiere mucho de los anteriores (de $3030 \mathrm{AP} \pm 90, \mathrm{AC} 677$ ), pero que resulta incoherente con el fechado de la capa subyacente.

Tabla 2. Instrumental óseo y especie utilizada.

\begin{tabular}{|l|c|c|c|c|c|}
\hline \multicolumn{9}{|c|}{ INSTRUMENTOS ÓSEOS } & TOTAL \\
\hline & AVE & GUANACO & MAMÍF. MARINO & MOLUSCO & 4 \\
\hline Punzones & 4 & & & & 1 \\
\hline Arpones & & & & 3 & 4 \\
\hline Cuentas & 1 & & & & 1 \\
\hline Frag. Pulim. ND & & 1 & & & \\
\hline
\end{tabular}


coincidiría con la época del año en que se produce el resurgimiento del bosque por la actividad de la savia, por lo cual se planteó la hipótesis de una ocupación relacionada con la explotación de recursos vegetales, especialmente la extracción de cortezas, cuyo procesamiento se realiza con mayor facilidad y eficiencia en esa estación del año, tal como la conocida por fuentes etnográficas para la confección de canoas, recipientes (cf. ref. in Orquera y Piana 1999b:336-338), así como maderas para arcos, mangos o astiles, etc. Esta hipótesis, sin embargo, no se corresponde con la ausencia de otro instrumental específico destinado a esa actividad, siendo el caso de las cuñas óseas, cuyo empleo para la extracción de cortezas está documentado para los Yámana. Por ello no se descartó, como hipótesis alternativa, la realización de alguna otra actividad sobre materiales perecederos, con recursos disponibles a fines del invierno o comienzos de primavera.

\section{OBJETIVOS, METODOLOGÍA Y RESULTADOS EXPERIMENTALES}

El principal objetivo del análisis de los materiales del IV Componente fue vincular las características tecnológicas (materia prima y técnicas de manufactura seleccionadas) y morfológicas de los artefactos (morfología general de las piezas y específica de los filos) con el análisis funcional de base microscópica. Los resultados de estos análisis fueron luego integrados en series tecnológicas (Leroi-Gourhan, 1971) utilizando el concepto de cadena operativa (Leroi-Gourhan, 1964), a fin de caracterizar las estrategias tecnológicas implementadas en el marco del proceso de gestión de los recursos líticos.

Los objetivos del análisis fueron ante todo:

- Realizar la caracterización morfotécnica de los diferentes grupos de instrumentos presentes y determinar su representatividad relativa;

- Determinar el tipo de materia prima y las técnicas de manufactura utilizadas para la confección de cada grupo de instrumentos;

- En el caso de los raspadores, dado el alto número de piezas y la gran homogeneidad descubierta en el conjunto, reevaluar los criterios en base a los cuales habían sido clasificados anteriormente, a la luz de los resultados del análisis tecnológico y funcional;
- Para la totalidad del instrumental, investigar si existía vinculación entre la materia prima seleccionada, la técnica de manufactura, la morfología del instrumento y el uso real dado a las piezas.

En cuanto al análisis funcional, sus objetivos específicos fueron:

- Establecer sobre qué material trabajó cada instrumento e identificar qué movimiento desarrolló durante su empleo;

- Definir el estado de los materiales trabajados y determinar la presencia o no de aditivos durante el trabajo;

- Distinguir el grado de incidencia de posibles alteraciones post-depositacionales en cada conjunto y para cada materia prima;

- Establecer la intensidad de uso de las piezas, reactivación y descarte, para evaluar las estrategias de gestión de las materias primas en relación con cada categoría de instrumentos.

Los criterios y variables seleccionados para el análisis tecnomorfológico son esencialmente coincidentes con los propuestos por Orquera y Piana (1986), ya que éstos han sido utilizados para el análisis de todo el material lítico de los sitios de la región.

En cuanto al análisis funcional de base microscópica, la metodología aplicada es la iniciada en la década de 1950 por S. Semenov y desarrollada luego por numerosos investigadores (v.g. Keeley 1980; Mansur 1983; Plisson 1985; véase ref. en Mansur 1999). Ella se basa sobre la identificación de macro y microrrastros de utilización sobre los filos de los instrumentos, combinada con el análisis de las alteraciones tecnológicas y post-depositacionales presentes en los artefactos.

Los análisis comprendieron el examen minucioso de todos los filos de los instrumentos, así como de la totalidad de filos complementarios (tanto retocados como naturales). Fueron realizados utilizando una lupa binocular Zeiss con aumentos de hasta 60X y un microscopio metalográfico Olympus $\mathrm{BHSM}$ con aumentos que van desde los 50X hasta los 500X.

\subsection{Caracterización tecnológica de las materias primas}

La mayor parte de las materias primas representadas en los conjuntos líticos de la costa norte del canal Beagle provienen de dos formaciones de 
la Cordillera Fueguina, que fueron intensamente plegadas y afectadas por un metamorfismo regional de grado bajo y de características dinámicas (Olivero y Martinioni, 2001).

Las rocas de mejor calidad para la talla proceden de la Formación Lemaire, definida por Borrello (1969), que tiene una amplia distribución en la Isla Grande (Figura 1). Esta formación, que data del Jurásico Tardío, está compuesta por variedad de tipos de roca de origen tanto volcánico como sedimentario, tales como cinerita, riolita, lutita, sílice (chert con radiolarios), tobas, arcilitas, que fueron sometidos a un proceso de metamorfismo regional. Por el ascenso orogénico andino, asomos de la Formación Lemaire quedaron expuestos a la erosión y fragmentos de sus componentes fueron transportados por acción glaciaria y depositados en estratos de diversas unidades sucesivas, más jóvenes, aun hasta en la actualidad.

Por tratarse de rocas con textura micro o criptocristalina y con fractura concoidea, en general son de buena calidad para la talla, salvo por su fisibilidad (debida a la existencia de planos de fragilidad internos producto del metamorfismo) que favorece la fractura en forma tabular y la formación de charnelas quebradas. Esta característica, especialmente notoria en el caso de las riolitas, dificulta la obtención de productos de talla (lascas) grandes con módulos delgados, confiriendo frecuentemente a los conjuntos resultantes un cierto aspecto de masividad. En las lascas, los filos delgados son sumamente frágiles; la experimentación funcional permitió comprobar la aparición de fracturas y desgranamiento, aun en procesos de utilización de leve intensidad, que dan por resultado un redondeamiento muy marcado (Mansur, 1999). Al contrario, las cineritas tienen mejores cualidades para la talla y filos más resistentes, pero se trata de materiales menos abundantes; además, resulta difícil distinguir los nódulos de riolita de los de cinerita por su aspecto externo, por lo cual su selección sólo es posible después de la apertura.

En menores proporciones se presentan otras materias primas, tales como pizarras, esquistos y otras vulcanitas, que corresponden a la Formación Yaghan. Se trata de materiales menos aptos para la talla, dado que frecuentemente se fracturan siguiendo planos laminares. Ello dificulta la realización del retoque sobre los filos, que se caracteriza por las charnelas quebradas y por su tendencia al desgranamiento. En cuanto a su resistencia ante el ataque de agentes mecánicos y químicos post-depositacionales, se trata de materiales sumamente frágiles, en los que se producen intensas pátinas y playas de abrasión (cf. infra).

En cuanto a los cuarzos, las vetas son ubicuas a lo largo de ambas Formaciones e incluso de unidades más recientes, dada su ubicación a lo largo del eje andino, con actividad magmática durante toda su gestación y posterior formación. Las vetas afloran en diferentes loci a lo largo de la costa, pero existe además gran disponibilidad de pequeños guijarros de cuarzo entre los rodados de playa, resultado del retrabajo sedimentario. Por las dimensiones de los guijarros, que muy rara vez superan los seis centímetros de largo, sólo resulta posible abrirlos mediante la técnica bipolar. En cuanto a su uso como materia prima, el trabajo experimental realizado ha mostrado que es posible obtener soportes adecuados y que los filos resultantes son altamente efectivos (cf. infra).

\subsection{Experimentación tecnológica y \\ funcional sobre guijarros de cuarzo}

No todas las materias primas producen rastros de uso similares, ni están sometidas a los mismos agentes de alteración. Por ello el proceso de análisis funcional se fundamenta en el conocimiento de las características petrográficas de las rocas utilizadas y de sus mecanismos de alteración, pero requiere también la contrastación de los rastros presentes en el material arqueológico mediante el desarrollo de trabajos experimentales específicos, en relación con cada problemática planteada (Mansur, 1999).

En este caso, resultaba indispensable llevar adelante un programa experimental sobre guijarros de cuarzo trabajados mediante talla bipolar. Sus principales objetivos fueron tres:

- Determinar el grado de dificultad para la obtención de buenos soportes sobre los guijarros de cuarzo disponibles localmente, mediante apertura por técnica bipolar;

- Generar patrones de referencia para la identificación de los rastros de uso sobre tales materias primas;

- Conocer el grado de efectividad de los filos de cuarzo en diversos procesos de uso sobre materiales locales, su resistencia, durabilidad, etc. 
La metodología y los resultados del programa experimental exceden el marco de este trabajo y por tanto serán presentados separadamente (Mansur y Lasa, 2005). Por ello sólo presentaremos aquí una mínima síntesis de las conclusiones relevantes para el análisis de los materiales del IV Componente.

En cuanto al primer objetivo, la confección de lascas a partir de guijarros de cuarzo mediante técnica bipolar es tarea fácil pero aleatoria. El modo de fractura de los guijarros depende de su constitución interna, ya que están afectados por la presencia de planos de fragilidad, fisuras, inclusiones, etc. También influye considerablemente su morfología exterior, ya que al no haber preparación de plataformas, el contacto del percutor con las porciones apicales del guijarro se produce primero en las irregularidades o saliencias. La aplicación de esta técnica de apertura produce frecuentemente lascas prismáticas con una morfología característica, con talón astillado, caras ortogonales planas y sin filos potencialmente utilizables. Algunos nódulos se fracturan produciendo lascas con filos potencialmente utilizables, así como masas centrales (núcleos bipolares) con extremos astillados, de sección rectilínea o arqueada, que pueden ser utilizados directamente o retocados por percusión directa a mano alzada para ser transformados en diferentes categorías de instrumentos.

Con respecto al segundo objetivo, de generar patrones de referencia funcional, se realizaron experimentos de utilización sobre maderas, pieles $y$ huesos, en diversas condiciones de uso. La experimentación permitió confirmar en el cuarzo local y sobre los materiales trabajados el marco general conocido para los rastros de uso sobre otras materias primas (Mansur, 1999; Mansur y Lasa, 2005).

En cuanto al tercer objetivo, de indagar sobre la efectividad de los filos en diversos procesos de uso sobre materiales locales, la experimentación permitió constatar que los filos de cuarzo son sumamente efectivos para el raspado tanto de maderas como de pieles. El microesquirlamiento que se produce durante el uso es escaso, pero cuando ocurre provoca una suerte de reavivado espontáneo del filo, transformándolo en altamente efectivo para extraer pequeños copos de la superficie de la madera o del interior del cuero, al contrario de lo que sucede cuando se utilizan filos de riolitas o cineritas. Los filos no sufren el redondeamiento rápido que se produce sobre los de otras materias primas; en consecuencia, la vida útil de los frentes de los raspadores de cuarzo es comparativamente más larga que en los de riolita o cinerita. En los raspadores experimentales los tiempos de uso máximos fueron de 60 minutos continuos, pero los filos seguían siendo efectivos luego de transcurrido ese lapso.

\section{ANÁLISIS TECNOMORFOLÓGICO}

\subsection{Materias primas y clases de artefactos líticos}

Las materias primas representadas en el conjunto lítico del IV Componente son variadas, pero entre ellas predomina el cuarzo de forma abrumadora, ya que este material supera el 85\% (Tabla 1). Entre los instrumentos retocados $(n=147)$, la gran mayoría ( $n=136,92,5 \%)$ fueron confeccionados en cuarzo (Tabla 3). Este predominio, sin embargo, no es homogéneo para todos los tipos de instrumentos. Al contrario, fue posible observar una gran homogeneidad en la selección de la materia prima para la confección de una categoría de instrumentos, los raspadores, y diversidad en las otras categorías. Del total del conjunto de raspadores ( $n=140)$, el 97,14\% $(n=136)$ fueron confeccionados en cuarzo, en tanto que los restantes (sólo 4) fueron confeccionados con cinerita.

Tabla 3. Materias primas de los instrumentos retocados.

\begin{tabular}{|l|c|c|c|c|c|c|c|c|}
\hline \multicolumn{9}{|c|}{ INSTRUMENTOS RETOCADOS } \\
\hline & QZ & PIZ & LU & SI & ESQ & CI & RIO & TOTAL \\
\hline Raspadores & 136 & & & & & 4 & 140 \\
\hline Raederas & & 1 & 1 & 1 & 1 & & 2 & 6 \\
\hline Punta bifacial & & & & & & & 1 & 1 \\
\hline Totales & 136 & 1 & 1 & 1 & 1 & 4 & 3 & 147 \\
\hline Porcentajes & 92,5 & 0,68 & 0,68 & 0,68 & 0,68 & 2,72 & 2,04 & 100,00 \\
\hline
\end{tabular}

QZ: cuarzo. PIZ: pizarra. LU: lutita. SI: sílice. ESQ: esquisto. CI: cinerita. RIO: riolita. 
Tabla 4. Restos de talla.

\begin{tabular}{|l|c|c|c|c|c|c|c|c|c|c|c|c|c|}
\hline \multicolumn{10}{|c|}{ RESTOS DE TALA } \\
\hline & BAS & ESQ & HOR & ANF & AR & CI & LU & ND & PIZ & QZ & RIO & SI & total \\
\hline Bipolares & & & & 0 & 0 & 3 & 0 & 0 & 0 & 240 & 0 & 1 & 244 \\
\hline Frags. bipolares & & & & 0 & 0 & 1 & 0 & 0 & 0 & 168 & 0 & 0 & 169 \\
\hline Lascas & & & & 1 & 0 & 56 & 21 & 0 & 16 & 272 & 67 & 1 & 434 \\
\hline Fragmentos & & & & 0 & 1 & 1 & 1 & 0 & 8 & 59 & 14 & 0 & 84 \\
\hline Litas y Debris & & & & & & 14 & 2 & & 12 & 632 & 15 & 2 & 677 \\
\hline $\begin{array}{l}\text { Microlascas y } \\
\text { microfrag. }\end{array}$ & & & & & & 104 & 20 & & & 825 & & & 949 \\
\hline TOTAL & 0 & 0 & 0 & 1 & 1 & 179 & 44 & 0 & 36 & 2196 & 96 & 4 & 2557 \\
\hline Porcentajes & 0,0 & 0,0 & 0,0 & 0,0 & 0,0 & 7,0 & 1,7 & 0,0 & 1,4 & 85,9 & 3,8 & 0,2 & 100,0 \\
\hline
\end{tabular}

BAS: basalto. ESQ: esquisto. HOR: hornblendita. ANF: anfibolita. AR: arcilita. CI: cinerita.

LU: lutita. ND: no determinable. PIZ: pizarra. QZ: cuarzo. RIO: riolita. SI: sílice.

Lascas y fragmentos: $>2 \mathrm{~cm}$. Litas y debris: entre 2 y $0,5 \mathrm{~cm}$. Microlascas y microfrag: $<0,5 \mathrm{~cm}$.

Las raederas son excesivamente escasas en comparación con la cantidad de raspadores. Entre ellas hay representación de prácticamente todas las rocas de la Formación Lemaire: dos de riolita, una de sílice, una de lutita, una de pizarra y una de esquisto. La única punta bifacial descubierta fue confeccionada en riolita (Tabla 3).

Entre los restos de talla ( $\mathrm{n}=2557$, incluyendo bipolares y percusión a mano alzada), la materia prima mejor representada es también el cuarzo $(85,9 \%)$. Hay sólo $7 \%$ de cinerita, 3,8\% de riolita, $1,7 \%$ de lutita, $1,4 \%$ de pizarra, cuatro restos de sílice, uno de anfibolita y uno de arcilita (Tabla 4). Algo similar sucede con los núcleos $(n=7)$, entre los cuales la mayoría (5) son de cuarzo (dos de ellos reparan entre sí). Contabilizamos como núcleos sólo a los enteros y fragmentados, mientras que los pequeños fragmentos se consideran entre los restos de talla.

Para el análisis de los restos de talla, a las categorías por tamaño que se utilizan habitualmente para clasificar lascas (piezas "muy grandes", "grandes", "medianas", "chicas" y "muy chicas", sensu Aschero 1975, Orquera y Piana 1986), se agregó una subdivisión en la última, que permite considerar por separado las piezas inferiores a $0,5 \mathrm{~cm}$ y las comprendidas entre 0,5 y $2 \mathrm{~cm}$. Para cada categoría tecno-dimensional, la representación del cuarzo se discrimina del siguiente modo (Tabla 4):

- Tamaño superior a $2 \mathrm{~cm}$ : "lascas" y "fragmentos", 931 piezas, de las cuales 739 (79,35\%) son de cuarzo. Sólo hay 24 de pizarra, 22 de lutita, 2 de sílice, 1 de arcilita, 1 de anfibolita, 61 de cinerita y 81 de riolita.
- Tamaño comprendido entre 0,5 y $2 \mathrm{~cm}$ : "lasquitas" y "débris" (incluye los pequeños fragmentos no reconocibles como lasquitas, así como las lasquitas fragmentadas en las que falta el talón), 677 piezas, de las cuales 632 son de cuarzo.

- Tamaño inferior a 0,5 cm: "microlascas" (con talón conservado) y "microfragmentos" (incluye también los pequeños fragmentos no reconocibles como microlascas, así como los fragmentos de microlascas en los que falta el tálón), 949 piezas de las cuales 825 son de cuarzo.

\subsection{Instrumentos retocados}

Definimos a los raspadores como instrumentos líticos que presentan un borde activo corto constituido por retoques continuos que forman filos de línea entera, recta a convexa, con bisel unifacetado asimétrico de ángulo intermedio a recto (superior a los $35^{\circ}$ ). Si bien en los conjuntos del canal Beagle el grupo constituye un continuum de formas y tamaños, sin límites definidos, habitualmente se han diferenciado en él las siguientes categorías (Orquera y Piana, 1988 en adelante):

- Raspadores no estandarizados: son aquellos raspadores en los cuales -salvo por lo que hace a la confección del filo activo- no hay alteración sensible de la morfología de la forma base, por lo que el perímetro de las piezas y sus relaciones largo - ancho - espesor son muy variables. También se incluyen dentro de esta categoría aquellos raspadores sobre lascas laminares u hojas con retoque terminal restringido, así como los raspadores confeccionados sobre clastos naturales, sobre núcleos o fragmentos 
de ellos o sobre lascas con fracturas múltiples en las que resulta prácticamente imposible caracterizar la forma base;

- Raspadores cortos o chicos: son aquellos en los que resulta notoria la búsqueda de tamaños chicos (por lo general menos de $3 \mathrm{~cm}$ de largo) y la adopción repetitiva de formas subcirculares o unguiculares. Los primeros se obtienen partiendo de formas base originalmente cortas o intencionalmente fragmentadas; las segundas mediante la extensión del retoque sobre los bordes laterales. En consecuencia, la forma general del fragmento lítico que sirvió como forma base suele estar modificada de modo proporcionalmente más extenso que en los otros casos;

- Raspadores microlíticos: constituyen una variedad de los raspadores cortos caracterizada porque la dimensión mayor de los instrumentos no alcanza los $2 \mathrm{~cm}$, sin que difieran las demás características morfotécnicas;

- Raspadores largos: son raspadores terminales confeccionados sobre lascas alargadas o láminas, aprovechando su tendencia hacia bordes laterales rectos o suavemente convexos, paralelos o subparalelos. El retoque puede ser corto o extendido. Frecuentemente presentan filos complementarios naturales o retocados. En esta categoría entran también objetos que en otros contextos suelen ser llamados raspadores "de hocico" o "de hombro", pero su escaso número y poca repetición en los conjuntos de la zona del canal Beagle no justifican aislarlos como categoría diferente.
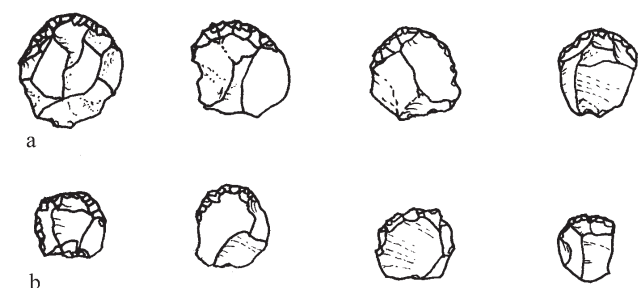

$\mathrm{b}$
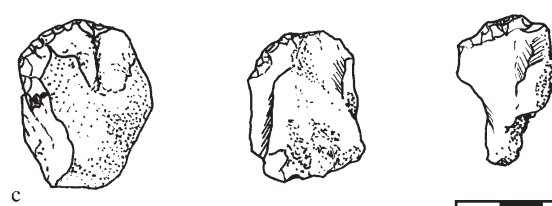

Fig. 3. Raspadores arqueológicos. a: chicos. b: micro. c: no estandarizados.
Tabla 5. Tipos de raspadores.

\begin{tabular}{|l|c|c|c|c|}
\hline \multicolumn{5}{|c|}{ FRAGMENTACIÓN DE LOS RASPADORES } \\
\hline Tipo & Entero & Fragm & Fto. & Total \\
\hline Rasp. chico & 52 & 15 & 1 & 68 \\
\hline Rasp. micro & 40 & 19 & 3 & 62 \\
\hline Rasp. no estand. & 7 & 3 & & 10 \\
\hline
\end{tabular}

La clasificación de los raspadores del IV Componente en las categorías antes señaladas permitió comprobar que éstos se reparten prácticamente por mitades entre las categorías "chico" $(n=68$, 48,57 \%) y "microlítico" ( $\mathrm{n}=62,44,28 \%)$, con sólo 10 raspadores no estandarizados (7,14\%) y ausencia total de raspadores largos (Fig. 3 y Tabla 5).

Contrariamente a los raspadores, el conjunto de las raederas se caracteriza por su diversidad morfológica y por sus grandes dimensiones, concentradas en módulos medianos o grandes. Está representado por 6 piezas: 4 raederas simples convexas (una de ellas convexa irregular), una simple cóncava y una convergente.

La punta bifacial es triangular alargada, con pedúnculo de base inclinada (con respecto al eje longitudinal) y aletas asimétricas. Presenta una fractura transversal con lengüeta, de superficie irregular, en el extremo distal, característica de impacto apical, que puede haberse producido al ser arrojada o por una caída.

\section{a) Fragmentación y conservación}

El grado de fragmentación de las piezas fue tomado en base a tres categorías: piezas enteras (cuando se conserva más del 80\% de la forma inicial), piezas fragmentadas (cuando se conserva entre el $50 \%$ y el $80 \%$ ) y fragmentos (menos del $50 \%$ de la forma inicial estimada).

En cuanto a los raspadores, es notorio el alto grado de fragmentación del conjunto. Hay 37 raspadores fragmentados $(26,42 \%)$ y 4 fragmentos de raspador $(2,85 \%)$. En la mayor parte de los casos no fue posible saber si las fracturas se produjeron durante el uso, ya que ellas no afectan filos retocados o utilizados. Dadas las características de la materia prima enunciadas al comienzo, es altamente probable que muchas de las fracturas sean previas a la formatización del raspador, producidas por accidentes de talla durante la preparación de 
Tabla 6. Dimensiones en raspadores y raederas.

\begin{tabular}{|l|c|c|c|c|c|}
\hline \multicolumn{5}{|c|}{ DIMENSIONES DE LOS INSTRUMENTOS RETOCADOS } \\
\hline & $\begin{array}{c}\text { Muy chico } \\
>=2 \mathrm{~cm}\end{array}$ & $\begin{array}{c}\text { Chico } \\
2,1 \mathrm{a} 4 \mathrm{~cm}\end{array}$ & $\begin{array}{c}\text { Mediano } \\
4,1 \mathrm{a} 8 \mathrm{~cm}\end{array}$ & $\begin{array}{c}\text { Grande } \\
>8 \mathrm{~cm}\end{array}$ & Total \\
\hline Raspadores & 62 & 78 & & & 140 \\
\hline Raedera & $44,28 \%$ & $55,71 \%$ & & 3 & $100 \%$ \\
\hline & & & $30 \%$ & $50 \%$ & 6 \\
\hline
\end{tabular}

Tabla 7. Dimensiones de los raspadores.

\begin{tabular}{|l|c|c|c|c|}
\hline \multicolumn{5}{|c|}{ DIMENSIONES DE LOS RASPADORES } \\
\hline Dimensiones & Microlíticos & Chicos & No estand. & TOTAL \\
\hline $0-1 \mathrm{~cm}$ & 0 & & & 0 \\
\hline $1,1-1,5 \mathrm{~cm}$ & 6 & & & 6 \\
\hline $1,6-2 \mathrm{~cm}$ & 51 & & & 51 \\
\hline $2,1-2,5 \mathrm{~cm}$ & & 55 & & 55 \\
\hline $2,6-3 \mathrm{~cm}$ & & 18 & & 18 \\
\hline $3,1-3,5 \mathrm{~cm}$ & & & 9 & 9 \\
\hline $3,6-4 \mathrm{~cm}$ & & & 1 & 1 \\
\hline & 57 & 73 & 10 & 140 \\
\hline
\end{tabular}

la forma base. Para cada subgrupo morfométrico, la fragmentación se discrimina según las categorías indicadas en la Tabla 5. Entre las raederas, hay tres enteras y tres fragmentadas.

El estado de conservación de los materiales a escala macroscópica varía según la materia prima. En el caso de las piezas de cuarzo, la mayoría de ellas posee rastros de alteración posdepositacional, pero éstos son siempre menos intensos que los que aparecen sobre las otras materias primas. Las alteraciones más representadas son el lustre de suelo, abrasión, pátina amarilla y pátina negra. Hay también algunos casos de probable termoalteración, pero no se observaron piezas quemadas o calcinadas. Tampoco se detectaron piezas rodadas que puedan evidenciar procesos de transporte postdepositacional.

\section{b) Dimensiones}

El análisis de las dimensiones de los instrumentos mostró su tendencia a concentrarse en los módulos muy chicos y chicos (raspadores), o medianos y grandes (raederas) (Tabla 6).

En cuanto a los raspadores, éstos presentan gran homogeneidad en cuanto a morfología y dimensiones. El 75,7\% de las piezas $(\mathrm{N}=106)$ tienen largos comprendidos entre 1,5 y $2,5 \mathrm{~cm}$. Hay sólo 6 raspadores con largo inferior a $1,5 \mathrm{~cm}(4,3 \%)$, en
Tabla 8. Módulos de espesor en raspadores y raederas.

\begin{tabular}{|l|c|c|c|c|}
\hline \multicolumn{5}{|c|}{ MÓDULOS DE ESPESOR } \\
\hline & $\begin{array}{c}\text { Poco } \\
\text { espeso }\end{array}$ & Espeso & $\begin{array}{c}\text { Muy } \\
\text { espeso }\end{array}$ & Total \\
\hline Raspador & 2 & 23 & 115 & 140 \\
$1,42 \%$ & $16,42 \%$ & $82,14 \%$ & $100 \%$ \\
\hline Raedera & 2 & 4 & & 6 \\
& $33,3 \%$ & 66,6 & & $100 \%$ \\
\hline
\end{tabular}

tanto que $28(20 \%)$ superan los $2,5 \mathrm{~cm}$. Si se consideran las categorías morfométricas mencionadas anteriormente, es posible observar que la mayor parte de los raspadores microlíticos tienen largos que se acercan al límite de $2 \mathrm{~cm}$ y que la mayoría de los raspadores chicos también se acerca a los 2 $\mathrm{cm}$ (Tabla 7).

El ancho de los raspadores se encuentra comprendido mayoritariamente en el rango entre 1,7 cm y $2,2 \mathrm{~cm}$ ( $n=78 ; 55,71 \%)$; siguen 38 raspadores $(27,14 \%)$ con anchos entre $1,1 \mathrm{~cm}$ y $1,6 \mathrm{~cm}$, y 24 raspadores (17,14\%) con ancho comprendido entre $2,3 \mathrm{~cm}$ y $3 \mathrm{~cm}$. El módulo de espesor (ancho/espesor) indica cierta masividad del conjunto, ya que el predominante es el muy espeso $(=2,7)$ con el $82,14 \%(n=115)$, seguido por el espeso $(2,8$ a 4,9$)$ con $16,42 \%(n=23)$ y finalmente 2 piezas $(1,42 \%)$ poco espesas $(=5)$ (Tabla 8$)$.

La relación del espesor con respecto al largo de los raspadores (espesor x100/largo) muestra predominio de los módulos intermedios (valores comprendidos entre 35 y 54,9), sobre los delgados (de 55 a 74,9) y los espesos (de 15 a 34,9) (Tabla 9).

Tabla 9. Relación espesor/largo en raspadores y raederas.

\begin{tabular}{|l|c|c|c|c|c|}
\hline \multicolumn{5}{|c|}{ RELACIÓN ESPESOR/LARGO } \\
\hline & Delgado & Interm. & Espeso & Muy esp. & Total \\
\hline Raspador & 12 & 91 & 37 & 0 & $\begin{array}{c}140 \\
100 \%\end{array}$ \\
\hline Raedera & & & 3 & 3 & $\begin{array}{c}6 \\
100 \%\end{array}$ \\
\hline
\end{tabular}


Tabla 10. Forma base de los instrumentos retocados.

\begin{tabular}{|l|c|c|c|c|c|c|}
\hline \multicolumn{7}{|c|}{ FORMA BASE DE LOS INSTRUMENTOS RETOCADOS } \\
\hline \multicolumn{7}{|c|}{ PERCUSIÓN DIRECTA PERCUSIÓN BIPOLAR } \\
\hline \multirow{2}{*}{ Raspadores } & L & LBN & LDN & BIL & BIN & TOTAL \\
\hline \multirow{2}{*}{ Raederas } & 34 & 14 & 24 & 53 & 15 & 140 \\
& $24,28 \%$ & $10 \%$ & $17,14 \%$ & $37,85 \%$ & $10,71 \%$ & $100 \%$ \\
\hline
\end{tabular}

L: lasca. LBN: lasca con borde de núcleo. LDN: lasca con dorso natural. BIL: lasca bipolar. BIN: núcleo bipolar.

Tabla 11. Formas base de los raspadores.

\begin{tabular}{|l|c|c|c|c|c|c|}
\hline \multicolumn{7}{|c|}{ RELACIÓN TIPO /SOPORTE } \\
\hline & L & LBN & LDN & BIL & BIN & TOTAL \\
\hline Raspador Chico & 15 & 5 & 11 & 29 & 8 & 68 \\
\hline Raspador Micro & 18 & 9 & 9 & 22 & 4 & 62 \\
\hline Raspador no Est. & 1 & 0 & 4 & 2 & 3 & 10 \\
\hline \multirow{2}{*}{ TOTAL } & 34 & 14 & 24 & 53 & 15 & 140 \\
& $(24,28 \%)$ & $(10 \%)$ & $(17,14 \%)$ & $(37,85 \%)$ & $(10,71 \%)$ & $(100 \%)$ \\
\hline
\end{tabular}

\section{c) Formas base}

Este criterio develó una alta homogeneidad en el conjunto de los raspadores, con un alto porcentaje de formas obtenidas por percusión bipolar (Tablas $10 \mathrm{y}$ 11). Sin embargo cabe consignar que en las categorías lasca de talla bipolar (BIL) y núcleo o masa central bipolar (BIN), incluimos solamente a aquellas piezas con signos evidentes de técnica bipolar. Cuando se trata de piezas fracturadas o de pequeños fragmentos en los cuales no se conservan rasgos que indiquen que fueron obtenidas por técnica bipolar o por percusión a mano alzada, optamos por incluirlos en las categorías lasca (L), lasca con dorso natural (LDN) o lasca con flanco o borde de núcleo (LBN), según corresponda. Entre las raederas, sólo la convergente (sílice) presenta signos de técnica bipolar, en tanto que las restantes fueron confeccionadas sobre lascas obtenidas por percusión a mano alzada.

\section{d) Morfología en vista dorsal}

La morfología de los soportes en vista dorsal muestra diferencias entre los tres subgrupos de raspadores y las raederas. Entre los raspadores chicos, el mayor porcentaje está representado por cara dorsal alargada (31 piezas), seguida por la subcircular o unguicular (17), ancha (12) y oblicua (8). Los raspadores microlíticos, en cambio, tienen mayoritariamente cara dorsal subcircular (34), seguida por la ancha (12), alargada (11) y oblicua (4). Los raspadores no estandarizados poseen cara dorsal alargada (8), excepto dos casos (2) con cara dorsal oblicua. Entre las raederas, la cara dorsal es alargada en 5 casos y ancha sólo en uno (Tabla 12).

\section{e) Tipos de talones}

La mayor parte de los soportes de los raspadores presenta talón astillado ( $n=79,56,42 \%)$, en relación directa con otros rasgos de aplicación de la técnica bipolar. En 26 casos (18,57\%) el talón está ausente por fractura o por retoque. Entre los restantes, 17 soportes $(12,14 \%)$ tienen talón liso, 6 piezas (4,28\%) presentan talón puntiforme, 8 (5,71\%) talón natural y hay $4(2,85 \%)$ no determinables.

Entre las raederas, hay 4 talones astillados y 2 talones naturales.

Tabla 12. Morfología de cara dorsal.

\begin{tabular}{|l|c|c|c|c|c|c|}
\hline & Alargada & Subcirc. & Ancha & Oblicua & No det. & Total \\
\hline Raspador Chico & 31 & 17 & 12 & 8 & & 68 \\
\hline Raspador Micro & 11 & 34 & 12 & 4 & 1 & 62 \\
\hline Raspador no Est. & 8 & & & 2 & & 10 \\
\hline Raederas & 5 & & 1 & & & 6 \\
\hline
\end{tabular}


Tabla 13. Filos de raspadores y raederas.

\begin{tabular}{|l|c|c|c|c|}
\hline & FILO DISTAL & FILO DERECHO & FILO IZQUIERDO & TOTAL FILOS \\
\hline RASPADORES & 124 & 11 & 8 & 143 \\
\hline RAEDERAS & 2 & 3 & 2 & 7 \\
\hline
\end{tabular}

f) Inclinación de los talones

En cuanto a la inclinación de los talones entre los raspadores hay $16,38 \%$ de talones rectos (que prácticamente se corresponden con los talones lisos y naturales), 2 oblicuos y 1 muy oblicuo. Se contabilizan como no determinables las inclinaciones del $46,42 \%$ de los talones de los raspadores, que corresponden a los 79 soportes con talón astillado. El 25\% del conjunto reúne los soportes en los que el talón es puntiforme o está ausente.

Entre las raederas los dos talones naturales son rectos.

\section{g) Número de filos}

En la mayoría de los casos fue formatizado sólo un filo, aun cuando la lasca soporte tuviese otros filos utilizables. Del conjunto de 140 raspadores, sólo tres presentan filos complementarios, dos son filos naturales y uno es un raspador doble (con filos alternos, uno sobre la cara dorsal y otro sobre la ventral). En cuanto a la situación de los filos ( $\mathrm{n}=143), 124(86,71 \%)$ tienen filos distales, 11 $(7,7 \%)$ derechos y $8(5,6 \%)$ izquierdos.

En cuanto a las raederas, sólo una tiene dos filos (convergente). De los siete filos considerados, tres son derechos, dos izquierdos y dos distales (Tabla 13).

\section{h) Longitud de los filos y extensión del retoque}

La longitud de los filos fue tomada sobre la cuerda del arco. En el caso de los raspadores chicos ésta se encuentra comprendida entre los 11 $\mathrm{mm}$ y los $28 \mathrm{~mm}$; para los raspadores microlíticos va de $9 \mathrm{~mm}$ a $22 \mathrm{~mm}$, y finalmente entre los no estandarizados es de $11 \mathrm{~mm}$ a $23 \mathrm{~mm}$. Los filos de las raederas tienen longitudes comprendidas entre $35 \mathrm{~mm}$ y $89 \mathrm{~mm}$.

En cuanto a la extensión del retoque, también hay diferencias entre las diferentes categorías de raspadores: los no estandarizados todos poseen en su totalidad retoque corto; los raspadores chicos y microlíticos tienen en su mayoría retoque corto y en menor proporción retoque extendido; en tanto que con retoque restringido sólo hay 10 raspadores que pertenecen a las categorías chico y microlítico. No hay ningún raspador con retoque perimetral completo. Entre las raederas, el retoque es largo en 3 casos, corto en 3 y extendido sólo en uno.

\section{i) Características del retoque}

Se observó gran similitud en cuanto al tipo de retoque entre los raspadores, ya que predomina el escalonado $(n=101)$, frecuentemente asociado a frentes de ángulo recto o intermedio. El resto de los raspadores tiene retoque escamoso irregular (39) y hay un solo caso de retoque subparalelo. Entre las raederas, los filos tienen retoque escamoso irregular y hay tres 3 casos con retoque escalonado (Tabla 14).

En cuanto al ángulo del retoque, los ángulos rectos $\left(70^{\circ}-95^{\circ}\right)$ predominan entre los raspadores $(\mathrm{N}=105,74,46 \%)$. Hay 35 con ángulo intermedio $\left(35^{\circ}-70^{\circ}\right)$ y sólo uno presenta un ángulo de retoque obtuso $\left(>95^{\circ}\right)$. Entre las raederas, el ángulo de retoque predominante es el intermedio $(n=6)$ (Tabla 15).

Finalmente, en cuanto a la posición del retoque, en todos los raspadores es directo (sobre la cara dorsal), salvo uno de los filos del raspador doble. En el caso de las raederas, todos son directos.

Tabla 14. Retoque en raspadores y raederas.

\begin{tabular}{|l|c|c|c|c|c|}
\hline \multicolumn{7}{|c|}{ TIPOS DE RETOQUE } \\
\hline & $\begin{array}{c}\text { ESCAMOSO } \\
\text { IRREGULAR }\end{array}$ & ESCALONADO & $\begin{array}{c}\text { SUBPARA } \\
\text { LELO }\end{array}$ & $\begin{array}{c}\text { FILOS } \\
\text { NATURALES }\end{array}$ & TOTAL FILOS \\
\hline RASPADORES & 39 & 101 & 1 & 2 & 143 \\
\hline RAEDERAS & 4 & 3 & & & 7 \\
\hline
\end{tabular}


Tabla 15. Ángulos de retoque en raspadores y raederas.

\begin{tabular}{|c|c|c|c|c|c|}
\hline \multicolumn{6}{|c|}{ ÁNGULOS DEL RETOQUE } \\
\hline & $\begin{array}{l}\text { Agudo } \\
\left(<35^{\circ}\right)\end{array}$ & $\begin{array}{c}\text { Intermedio } \\
\left(35^{\circ}-70^{\circ}\right)\end{array}$ & $\begin{array}{c}\text { Recto } \\
\left(70^{\circ}-95^{\circ}\right)\end{array}$ & $\begin{array}{l}\text { Obtuso } \\
\left(>95^{\circ}\right)\end{array}$ & $\begin{array}{c}\text { Total de filos } \\
\text { retocados }\end{array}$ \\
\hline Raspadores & & $\begin{array}{c}35 \\
24,82 \% \\
\end{array}$ & $\begin{array}{c}105 \\
74,46 \% \\
\end{array}$ & $\begin{array}{c}1 \\
0,70 \%\end{array}$ & $\begin{array}{c}141 \\
100 \%\end{array}$ \\
\hline Raederas & & $\begin{array}{c}6 \\
85,7 \%\end{array}$ & $\begin{array}{c}1 \\
14,28 \%\end{array}$ & & $\begin{array}{c}7 \\
100 \%\end{array}$ \\
\hline
\end{tabular}

\section{j) Reactivación}

Los criterios macroscópicos en base a los cuales se preclasificó a algunos filos como posiblemente reactivados $(n=46)$ fueron esencialmente el ángulo y el tipo de retoque. La mayor parte de los raspadores que presentaban ángulo de retoque recto $y$ tipo de retoque escalonado sugerían haber sido reactivados. Algunos de ellos $(n=8)$ mostraron luego rasgos microscópicos atribuibles a reactivación (cf. infra). Entre las raederas, una tiene retoque escamoso escalonado con signos de posible reactivación.

\subsection{Restos de talla: desechos y filos} potencialmente utilizables

El análisis tecnomorfológico de los restos de talla fue efectuado considerando los mismos criterios que para los instrumentos retocados, pero separándose además aquellos con filos potencialmente utilizables. Para este conjunto, consideramos como tales a aquellos filos que presentan secciones de al menos $2 \mathrm{~cm}$ de largo, medianamente rectilíneas y regulares, cuyas características los hacen aptos para la utilización. En tales casos, el análisis funcional permite discriminar entre los que fueron abandonados como desechos y aquellos que fueron utilizados como instrumentos.

En lo que respecta a las materias primas, entre los restos de talla $(n=2557$, incluyendo tanto productos bipolares como de percusión a mano alzada), el cuarzo también predomina de forma abrumadora $(85,9 \%)$. Los restos de cinerita sólo representan el 7\% y los de riolita el 3,8\%. Las otras materias primas (lutita, pizarra, sílice, anfibolita y arcilita) no alcanzan a totalizar el 3\% (Tabla 4).

Entre los restos de talla bipolar enteros y fragmentados ( $n=244)$, se contabilizaron 170 lascas bipolares y 74 núcleos o masas centrales bipolares (Tabla 16). En el 96,3\% de los casos, la materia prima es el cuarzo; hay sólo tres de cinerita y uno de sílice. Los fragmentos de talla bipolar $(\mathrm{n}=169)$, son prácticamente todos de cuarzo (hay sólo uno de cinerita). Entre los núcleos bipolares fueron identificados 17 que presentaban aristas medianamente regulares, que separamos como potencialmente utilizables a los efectos del análisis funcional; lo mismo sucedió con 12 lascas y fragmentos bipolares.

Los restos de talla de percusión a mano alzada $(n=2144)$ totalizan $78,73 \%$ del material lítico del IV Componente. Entre ellos, hay 518 lascas y fragmentos mayores de $2 \mathrm{~cm}, 677$ lasquitas y débris (inferiores a $2 \mathrm{~cm}$ ) y 949 microlascas (inferiores a $0,5 \mathrm{~cm}$ ). En este conjunto, el cuarzo también predomina de forma abrumadora ( $n=1788,83,39 \%)$, seguido por bajos porcentajes de cinerita $(8,16 \%)$ y riolita $(4,47 \%)$.

Entre las lascas y fragmentos mayores de $2 \mathrm{~cm}$ sólo se identificaron 7 con filos potencialmente utilizables. Se trata de lascas que presentan esquirlamiento macroscópico, que habían sido clasificadas como lascas con esquirlamiento sobre filo natural (lascas CESFN) y por ello las contabilizamos por separado. Las materias primas son 3 pizarras, 2 riolitas, una

Tabla 16. Instrumentos y restos de talla bipolar.

\begin{tabular}{|l|c|c|c|c|c|c|}
\hline \multicolumn{7}{|c|}{ INSTRUMENTOS Y RESTOS DE TALLA BIPOLAR } \\
\hline & BIL & $\%$ & BIN & $\%$ & TOTAL & $\%$ \\
\hline Raspadores & 53 & $11 \%$ & 15 & $3,1 \%$ & 68 & $14,1 \%$ \\
\hline Raederas & 1 & $0,20 \%$ & & & 1 & $0,20 \%$ \\
\hline Bipolares & 170 & $35,2 \%$ & 74 & $15,4 \%$ & 244 & $50,62 \%$ \\
\hline Frag. Bipolar & 164 & $34 \%$ & 5 & $1 \%$ & 169 & $35 \%$ \\
\hline Total bipolares & 388 & $80,49 \%$ & 94 & $19,50 \%$ & 482 & $100 \%$ \\
\hline
\end{tabular}


lutita y una clasificada como no determinable, ya que presenta pátina amarillenta que altera toda la superficie (aunque es probable que se trate de otra riolita). Se contabilizaron 7 núcleos, de los cuales 5 son de cuarzo, uno de lutita y uno de riolita.

El estudio de reparaciones y remontajes de los materiales resultó poco fructífero (debido especialmente a la gran cantidad de restos de pequeñas dimensiones, con fracturas tecnológicas, que se producen en la talla bipolar de los guijarros de cuarzo). Sólo fueron identificados tres conjuntos de piezas que reparan o remontan entre sí, uno formado por 7 lascas, otro por 4 lascas y uno por dos fragmentos de núcleo de cuarzo.

\section{ANÁLISIS FUNCIONAL}

El análisis funcional de base microscópica se funda esencialmente en la identificación de rastros que pueden ser clasificados en dos grupos (Mansur 1999):

- macrorrastros: también denominados esquirlamientos de filos, son modificaciones de los filos que se producen como consecuencia de su fractura, alterando su sección o delineación;

- microrrastros: son alteraciones de la superficie de los filos que se producen, en todo o en parte, por modificaciones de la estructura cristalina de la roca. Los clasificamos en tres tipos: redondeamiento o alisamiento de filos, estrías microscópicas y micropulidos.

Para los materiales arqueológicos del IV Componente, el análisis microscópico fue efectuado sobre todos los instrumentos retocados y sobre la totalidad de las lascas y productos bipolares con filos potencialmente utilizables. Permitió arribar a resultados generales en cuanto a cada uno de los criterios considerados en el análisis funcional y a determinaciones específicas para los instrumentos.

\subsection{Características de los rastros observados}

\section{a) Redondeamiento:}

En los raspadores de cuarzo, el redondeamiento del filo no es nunca demasiado intenso. En los frentes de los raspadores, los procesos de uso producen modificaciones por microesquirlamiento, originando negativos frescos, en una suerte de reavivado espontáneo del filo activo, ya que las propias microesquirlas arrastran consigo porciones del filo redondeado o alisado. Estas características son observables cuando se analiza el bisel con iluminación perpendicular y aumentos superiores a 200 X. En cuanto a las aristas de los negativos de microesquirlamiento, en los casos en que se alcanzó un alto grado de desarrollo de micropulido se observa también redondeamiento producido por el mayor contacto entre ellas y el material trabajado.

El redondeamiento de las otras aristas de los raspadores de cuarzo por factores post-depositacionales es ligero. En las otras materias primas, en cambio, en general hay alto grado de redondeamiento producido por alteraciones post-depositacionales.

\section{b) Esquirlamiento:}

En los raspadores de cuarzo se observó esquirlamiento en todos los filos utilizados. En la mayoría de las piezas el esquirlamiento es mediano o abundante y hay muy pocas con esquirlamiento escaso.

El microesquirlamiento es continuo en la mayoría de las piezas; sólo se observó esquirlamiento más espaciado (discontinuo) en las piezas que presentaban mayor grado de desarrollo del micropulido. El microesquirlamiento es siempre irregular; predominan las dimensiones inferiores a 0,66 mm. En cuanto a la morfología de los negativos, predominan los semicirculares; se observaron también algunos de tipo medialuna (melladuras) en piezas que no tuvieron uso y en frentes reactivados. Las terminaciones de los negativos son diversas, pero se observaron abundantes terminaciones abruptas.

En las otras materias primas el esquirlamiento es mediano, en la mayoría de los casos abundante. En las piezas confeccionadas en pizarras o esquistos, el microesquirlamiento es continuo, con predominio de los de tipo medialuna y de las con terminaciones abruptas. En riolita o sílice, en cambio, el esquirlamiento es mediano y más discontinuo, con morfologías semicirculares y en medialuna, pero con terminaciones más suavizadas.

\section{c) Estrías:}

Las estrías constituyen un rasgo de importancia entre los raspadores de cuarzo. Se trata principalmente del tipo de fondo rugoso, angosto profundo 
(estrías oscuras, medianas a largas), observable en iluminación perpendicular y con aumentos superiores a 200 X. En la mayoría de los casos se encuentran agrupadas, distribuidas a lo largo del filo activo y tienen orientación perpendicular u oblicua al filo. En las piezas que presentan alto grado de desarrollo del micropulido, se observaron también franjas de estrías cortas, perpendiculares y oblicuas, mayores de 0,66 mm.

En las otras materias primas prácticamente no se observaron estrías, a excepción de las producidas por abrasión.

\section{d) Micropulido:}

Entre los raspadores de cuarzo, sólo algunas piezas $(n=25)$ no presentan micropulidos de uso. Se trata de frentes que muestran esquirlamiento y rastros tecnológicos frescos (estrías, ondas de percusión, etc.), que fueron clasificadas como no utilizadas $y$ otras con rastros frescos de reactivación (sugiriendo que no fueron reutilizadas o escasamente reutilizadas después de la reactivación).

En los otros casos, los frentes presentan micropulidos cuyo grado de desarrollo varía a lo largo del filo. Esta variabilidad en el grado de desarrollo se debe a dos factores principales. Uno es el mayor contacto en las porciones salientes o sobreelevadas del filo, donde el grado de desarrollo alcanzado es superior al de las porciones con menor contacto. Otro es que al producirse abundante microesquirlamiento, el mismo remueve parcialmente el micropulido ya formado (al igual que sucede con la reactivación); el micropulido que se produce al continuar el trabajo se forma entonces, en algunos sectores, sobre superficies frescas y en otros sobre los remanentes del micropulido previo. Sin embargo hay que destacar que en la mayoría de las piezas analizadas hay sectores del filo que presentan un alto grado de desarrollo del micropulido.

Los micropulidos observados en general son planos y opacos (brillo mate), característicos del trabajo de material blando de origen animal. Además presentan superficie de aspecto rugoso y rasgos microtopográficos asociados tales como huecos semiesféricos y zonas con surcos superficiales paralelos entre sí, perpendiculares al filo, especialmente recurrentes en los biseles. Estos micropulidos son poco espesos (planos o intermedios), su extensión es marginal y la distribución es homogénea, con unas pocas excepciones de micropulidos en cúspides. Se observa micropulido en las concavidades de los negativos sólo en aquellas piezas que presentan un alto grado de desarrollo del micropulido; sin embargo el micropulido sobre las aristas de microesquirlamiento es frecuente en todo el conjunto.

Esta serie de rasgos del micropulido, asociada a las características de los demás tipos de macro y microrrastros analizados son característicos del trabajo de pieles. En cuanto al tiempo de uso de los instrumentos, la relación entre el grado de desarrollo del micropulido y el tiempo de uso no es directa, ya que otras variables influyen en su formación. Ante todo debe tenerse en cuenta que, a iguales tiempos de uso y características del material trabajado, el grado de desarrollo difiere según la materia prima del instrumento. En el caso de los frentes de los raspadores de cuarzo, el grado de desarrollo de los micropulidos así como las características de los otros macro y microrrastros asociados, indican acciones con cinemática transversal (filo en posición perpendicular a la dirección de utilización) y sugieren tiempos de uso relativamente largos o utilización reiterada.

\subsection{Determinación funcional}

A fin de evaluar los resultados del análisis funcional, resulta esencial discriminar los instrumentos clasificados como no determinables de los que efectivamente no han sido utilizados. Por ello clasificamos como No utilizadas sólo a aquellas piezas que conservan rasgos tecnológicos frescos (producidos por la talla), tales como ondas, estrías, marcas de impacto, etc. Incluimos en la categoría No determinable a aquellas piezas que no presentan micropulido o en las cuales éste tiene un muy escaso desarrollo, pero está enmascarado por alteraciones postdepositacionales que impiden la determinación segura. Al contrario, en los casos determinados como Uso seguro, el micropulido es diagnóstico y a partir de sus características propias y de los rasgos microtopográficos asociados resulta posible inferir el tipo de material trabajado, el movimiento efectuado y el ángulo de trabajo. En algunos casos, ciertos rastros han sido eliminados u obliterados por abrasión o esquirlamiento, pero se conserva parte del micropulido, siendo posible efectuar 
determinaciones de uso seguro. Finalmente, en la categoría Uso probable, se incluyen instrumentos en los cuales el grado de desarrollo del micropulido $y$ de sus rasgos asociados permite inferir alguna característica del material trabajado (material blando o duro, vegetal o animal) o cinemática, pero no resulta suficiente para efectuar la determinación completa (uso seguro).

\subsection{Resultados}

Los resultados del análisis funcional pusieron en evidencia, en primer término, una baja frecuencia de artefactos con alteraciones post-depositacionales severas, que hacen imposible la determinación funcional: sólo el 15,7\% del total. No obstante ello, es necesario resaltar que este porcentaje tan bajo obedece al hecho de la mayor resistencia del cuarzo (6,03\% de piezas alteradas entre los raspadores, en tanto que entre las piezas de otras materias primas se presenta alteración severa en el 53\%).

Entre los raspadores, la mayoría de las piezas conserva rastros de uso con diversos grados de desarrollo, en tanto que sólo 18 piezas fueron clasificadas como no usadas (Tabla 17). En cuanto a las raederas, también la mayoría $(n=4)$ conserva rastros de uso seguro (hay sólo 2 no determinables). En el caso de las lascas con filos naturales con esquirlamiento, la mayoría de las piezas $(n=5)$ presenta alteraciones producidas por diferentes procesos de alteración postdepositacionales (pátina amarillenta, abrasión, etc.) que impiden la determinación funcional, y hay 2 probablemente no utilizadas. Los núcleos bipolares analizados (cuarzo y cinerita) y los fragmentos de lascas bipolares (todas de cuarzo) tienen buen estado de conservación o un ligero lustre de suelo y en todos los casos presentan filos frescos que indican que no fueron utilizados. Finalmente, en cuanto a la punta bifacial, ésta presenta playas de abrasión postdepositacionales.

El análisis funcional de los raspadores demostró que la mayoría (65\%) fueron utilizados para trabajar pieles o cueros (Fig. 4 a y b); hay un caso de trabajo de hueso, 3 de acciones sobre material blando de origen animal y uno sobre madera (Tabla 18). En función de la distribución, orientación y extensión de los rastros de uso, fue posible determinar que todos los raspadores utilizados realizaron acciones transversales, con la cara ventral como cara de contacto y ángulos de trabajo intermedios a altos. La única excepción es un filo complementario de un raspador, que fue utilizado en modo de acción longitudinal.

En cuanto a las características del material trabajado, el aspecto de los micropulidos sugiere que los raspadores fueron utilizados bajo presión, para el raspado/adelgazamiento de cueros secos, probablemente de mamíferos continentales (gua-

Tabla 17. Grado de desarrollo de rastros de uso. Análisis funcional de los materiales.

\begin{tabular}{|l|c|c|c|c|c|}
\hline \multicolumn{5}{|c|}{ Grado de desarrollo de rastros de uso } \\
\hline & & $\begin{array}{c}\text { Grado } \\
1\end{array}$ & $\begin{array}{c}\text { Grado } \\
2\end{array}$ & $\begin{array}{c}\text { Grado } \\
3\end{array}$ & Total \\
\hline RASPADORES & & & & & \\
\hline No usados & 18 & & & & 18 \\
\hline Uso no determ. & & 22 & 0 & 0 & 22 \\
\hline Uso Probable & & 4 & 8 & 0 & 12 \\
\hline Uso seguro & & 3 & 51 & 34 & 88 \\
\hline Total & & & & & 140 \\
\hline RAED. Y LASCAS CESFN & & & & & \\
\hline No usadas & 2 & & & & 2 \\
\hline Uso no determ. & & 5 & & & 4 \\
\hline Uso seguro & & 3 & & & 11 \\
\hline Total & & & & & \\
\hline PUNTA BIFACIAL & & 1 & & & \\
\hline Uso no determ. & & & & & 17 \\
\hline BIPOLARES & & & & & \\
\hline No usados & & & & & \\
\hline
\end{tabular}



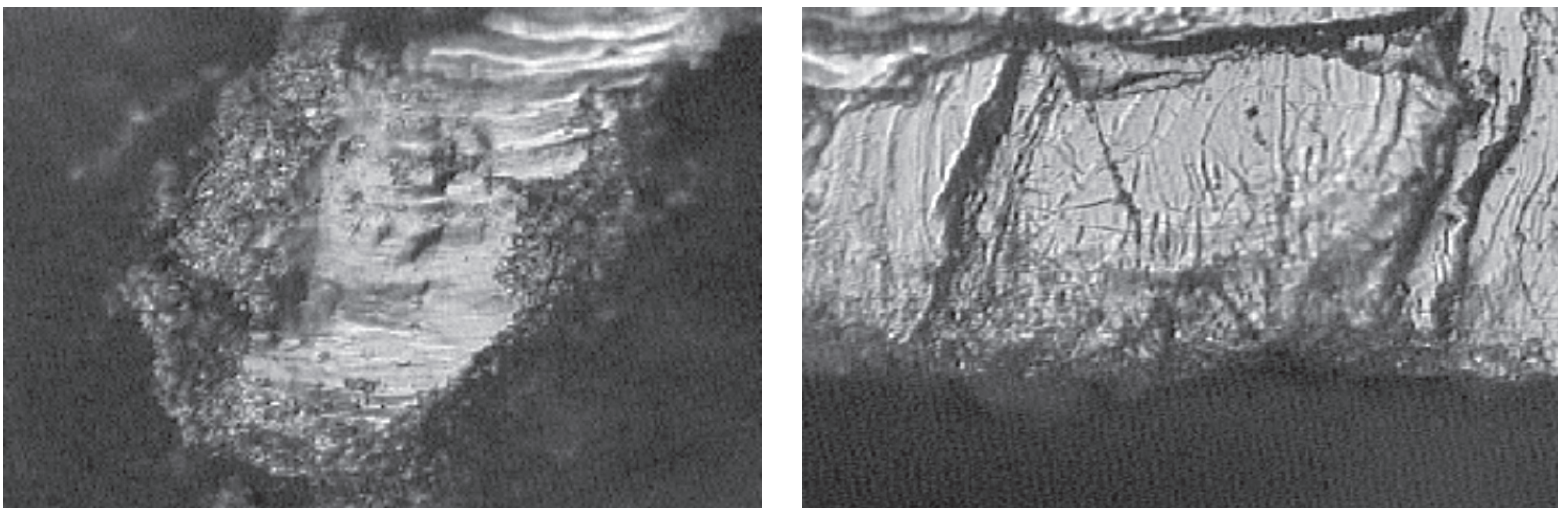

Fig. 4 a y b: Rastros de uso por raspado de pieles sobre el filo de dos raspadores de cuarzo del IV Componente.

Tabla 18. Utilización de los instrumentos determinables.

\begin{tabular}{|l|c|c|c|c|c|}
\hline \multicolumn{7}{|c|}{ Uso de los instrumentos determinables } \\
\hline & No usado & Piel & $\begin{array}{c}\text { Mat. blando } \\
\text { animal }\end{array}$ & Mat. vegetal & $\begin{array}{c}\text { Mat. duro } \\
\text { (hueso) }\end{array}$ \\
\hline Raspador & 18 & 91 & 3 & 1 & 1 \\
\hline Raedera simple & & & & 1 & \\
\hline TOTAL & 18 & 91 & 3 & 2 & 1 \\
\hline
\end{tabular}

naco, zorro, etc.) y no de mamíferos marinos. La abundancia de estrías podría indicar la existencia de polvo o el agregado de cenizas, pero dado el alto grado de microesquirlamiento observado, éstas podrían igualmente ser resultado del contacto bajo presión de la superficie del filo con las microesquirlas desprendidas de él. En ningún caso se detectaron indicios de agregado de aditivos tales como grasas, colorantes, etc.

Para evaluar la intensidad de uso de los raspadores, los criterios considerados fueron la utilización de filos complementarios y el grado de reactivación

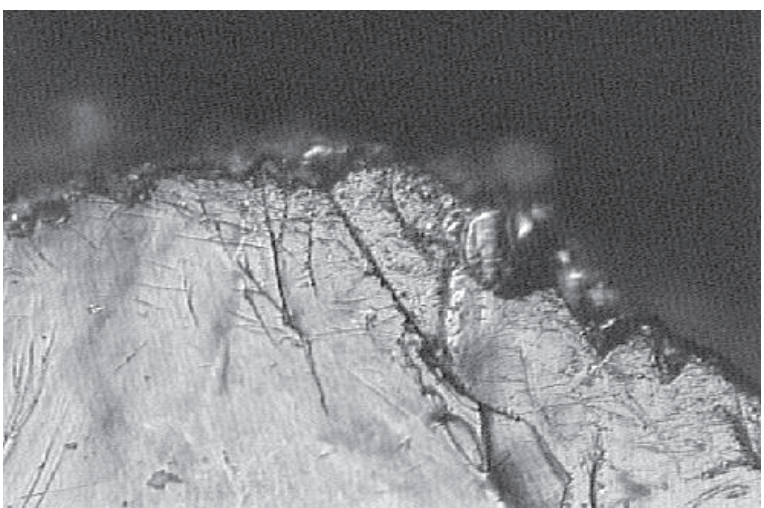

de los filos. En cuanto al primer criterio, los tres casos de filos complementarios existentes (uno también en raspador y dos filos naturales) muestran rastros de uso correspondientes al trabajo de pieles o cueros secos. Con respecto al segundo, para identificar correctamente la presencia o no de reactivación se tomaron en cuenta en primera instancia criterios macroscópicos, tales como el ángulo de filo y el tipo de retoque (en general filos rectos $\mathrm{u}$ obtusos con retoque escalonado), que fueron confirmados luego en función de los siguientes criterios microscópicos (Fig. 5):

Fig. 5 a y b: Rastros tecnológicos sobre filos de raspadores, asociados a rastros de uso sobre pieles.

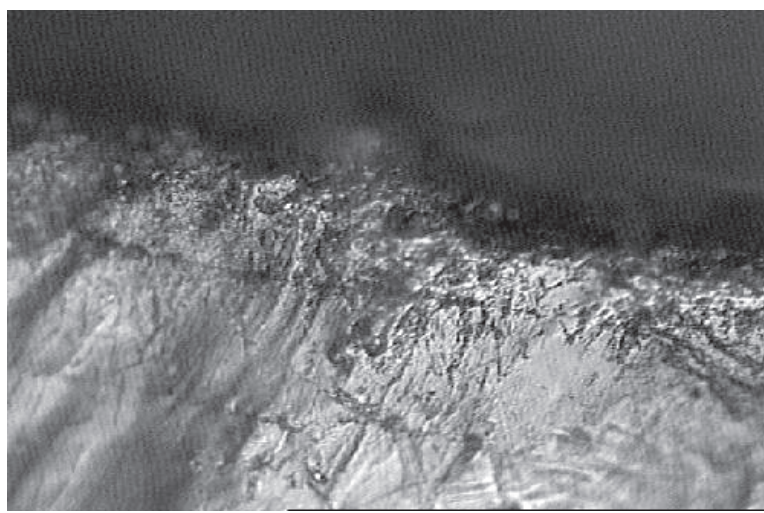


- presencia de microfracturas concéntricas características de impactos del retocador,

- existencia de sectores del filo que presentan rastros de uso combinados con partes frescas que exhiben rastros tecnológicos, o con zonas en las que el grado de desarrollo de los micropulidos es menor,

- existencia de estrías remanentes producidas por el trabajo de piel junto con bordes frescos.

Estos rasgos microscópicos sólo pudieron ser observados en aquellas piezas que no presentaban alteraciones post-depositacionales importantes.

En función de estos criterios se pudo comprobar que los filos de los raspadores presentan un alto grado de reactivación, que alcanza al 41,4\% $(n=48)$.

El análisis microscópico de las raederas reveló la existencia de alteraciones postdepositacionales que dificultan la determinación funcional, tales como lustre de suelo intenso, pátina y/o playas de abrasión. Sólo una presenta buen estado de conservación. En el aspecto funcional, solamente en dos casos no fue posible determinar si la pieza había sido o no utilizada. Por el contrario, en las otras raederas pudo determinarse que los filos, con ángulos intermedios y rectos, fueron utilizados con movimiento longitudinal, en acciones de corte. En la raedera de riolita, se observaron micropulido y rasgos microtopográficos asociados correspondientes al trabajo de madera. En los tres casos restantes (una sobre sílice, una sobre pizarra y una sobre lutita), sólo fue posible determinar con seguridad el modo de uso -gracias a la presencia de indicadores direccionales-, pero no el material trabajado, debido a la existencia de intensas playas de abrasión. Lo mismo ocurrió con el filo complementario (izquierdo) de la raedera convergente. Por las características de los rastros observados, resulta poco probable que pueda tratarse de trabajo sobre madera, salvo en acciones de corta duración. Al contrario, podría tratarse de procesamiento de recursos animales blandos o intermedios, tal el caso del faenamiento o el corte de pieles, cuyos rastros pueden ser fácilmente enmascarados por los procesos abrasivos postdepositacionales.

De modo sintético, los resultados obtenidos en relación con los objetivos de análisis propuestos pueden resumirse así:

- En cuanto a materiales trabajados y modos de uso, predominan las acciones longitudinales efectuadas con raederas y las transversales ejecutadas con raspadores; el trabajo de la madera con raederas fue documentado en un caso, en tanto que el de pieles con raspadores está ampliamente documentado (salvo 1 caso).

- En cuanto al estado de los materiales trabajados y la presencia o no de aditivos, se determinó que las pieles fueron trabajadas en estado seco (cuero) y no se detectaron aditivos. El trabajo de la madera corresponde a estado fresco.

- En cuanto al grado de incidencia de alteraciones post-depositacionales, se verificó un mejor estado de conservación del cuarzo, mediano en riolitas y cineritas y mal estado de conservación en lutitas y esquistos.

- En cuanto a la intensidad de uso, reactivación y descarte, para evaluar las estrategias de gestión de las materias primas en relación con cada categoría de instrumentos, se constató alta intensidad de uso, incluyendo reactivación, en los raspadores de cuarzo, y reactivación de los filos de raederas en sólo un caso.

\section{DISCUSIÓN DE RESULTADOS}

\subsection{Selección y provisión de materias primas líticas}

Con respecto a nuestro primer objetivo de análisis, que era determinar qué tipo de materia prima fue utilizada prioritariamente para la confección de cada grupo de instrumentos, se constató una gran homogeneidad de materia prima para una categoría de instrumentos, la de los raspadores, que fueron confeccionados prioritariamente en cuarzo, y diversidad de materias primas para las otras categorías (raederas y lascas CESFN). En el caso de estas últimas, tal comportamiento es similar al de otros conjuntos artefactuales de la región, no así en el de los raspadores.

En cuanto al aprovisionamiento, la morfología de los nódulos utilizados que se infiere a partir de los tamaños de los productos y reservas de cortezas, sugiere que la provisión de materias primas no fue efectuada en los afloramientos primarios sino en las formaciones redepositadas próximas a la costa, donde los materiales fueron transportados por la acción de glaciares y torrentes y se encuentran disponibles en forma de clastos y cantos rodados, 
en playas y en cortes naturales de formaciones morrénicas. En consecuencia, la provisión pudo haber sido efectuada en las inmediaciones del sitio, corroborando el modelo propuesto sobre la base del análisis de materiales de Túnel VII (Clemente et al. 1996; Clemente y Terradas, 1993; Mansur y Vila, 1993; Piana et al. 1996; Terradas 1996), extendido luego a otros yacimientos de la región (Orquera y Piana, 1999a; Álvarez, 2003). Llama la atención sin embargo el caso de los guijarros de cuarzo, ya que si bien están presentes en estas formaciones, ellos no son abundantes y tampoco hemos podido localizar concentraciones particulares. En consecuencia, la provisión de tales materiales implica un esfuerzo de búsqueda, orientado a la selección de guijarros de cuarzo con morfología y tamaño adecuados.

\subsection{Uso y conservación de la materia prima}

En cuanto a las técnicas de manufactura que se deducen del análisis de los instrumentos y restos de talla, se evidencia la existencia de dos técnicas de apertura de nódulos, en relación directa con la materia prima: percusión apoyada bipolar para los nódulos de cuarzo, y percusión directa a mano alzada para los otros materiales. Esta relación no parece depender de una característica intrínseca de la roca (propiedades estructurales) sino de la forma en que cada una se presenta en las zonas de provisión propuestas tal como se menciona en la descripción de las respectivas cadenas operativas ( $c f$. infra).

Si se considera el caso de las raederas, sólo dos de ellas (una de lutita y una de cinerita) pueden haber sido confeccionadas en el sitio, ya que faltan totalmente los productos de talla y terminación (retoque) de las otras cuatro. Sin embargo, teniendo en cuenta la disponibilidad de materia prima lítica en las inmediaciones del sitio, la falta de núcleos y productos de talla que completen el registro excavado no indica forzosamente instrumental "conservado" (sensu Binford, 1979); alternativamente puede proponerse que las fases iniciales de reducción se hayan desarrollado en la playa. Esto también fue propuesto para el caso del sitio Túnel VII, cuando discutimos el concepto de "hábitat" y la incorporación de la zona aledaña al sitio como espacio social (Mansur y Vila, 1993) y recientemente para Ponsonby (Pigeot, 2003).
5.3. Cadenas operativas para la producción de instrumentos líticos

La producción de instrumentos líticos fue realizada siguiendo cuatro cadenas operativas ( $c f$. Leroi-Gourhan, 1964) diferentes, que se deducen a partir del análisis de las formas base de los instrumentos líticos y de los restos de talla, así como del estudio de reparaciones y remontajes. Las cadenas operativas identificadas se encuentran estrechamente vinculadas con criterios tales como el modo en que se presenta la materia prima, el tipo, la morfología y las dimensiones del soporte que se desea obtener, las posibilidades de cada técnica de apertura o de reducción, etc. (Mansur et al. 2004).

La primera estuvo destinada a la producción de lascas grandes, en rocas de diversa litología, tales como cineritas, riolitas, lutitas, sílices, etc. Estas materias primas se encuentran disponibles en las formaciones redepositadas antes mencionadas, en forma de clastos o guijarros de dimensiones variables. La técnica de manufactura utilizada fue la percusión directa. En este proceso se seleccionaron lascas internas, en general delgadas, en la búsqueda de filos largos, que fueron utilizados directamente o retocados para la confección de raederas. Entre estos materiales, las cineritas son al mismo tiempo las que presentan mejores cualidades para la talla y las que brindan filos más resistentes para la utilización, pero son relativamente escasas en las inmediaciones del sitio, en comparación con las riolitas. En cuanto a la selección de materiales como lutitas y esquistos, de pobre calidad para la talla y cuyos filos son poco resistentes, probablemente uno de los criterios es que pueden hallarse nódulos de dimensiones suficientes como para producir lascas delgadas (dado que se fracturan siguiendo planos laminares) de los tamaños deseados.

La segunda cadena operativa estuvo destinada a la producción de productos pequeños, espesos, a partir de guijarros de cuarzo que se trabajaron mediante percusión apoyada bipolar. Estos productos fueron seleccionados para la confección de raspadores chicos y microlíticos, en los cuales las formas base utilizadas fueron tanto lascas como masas centrales (núcleos bipolares). En la serie analizada, el 40,20\% de las formas base de los raspadores muestra los rasgos característicos producidos por la aplicación de la técnica bipolar. 
El uso de la técnica bipolar guarda relación directa con las características morfológicas y dimensionales de los guijarros de cuarzo disponibles en los depósitos secundarios de las proximidades de la localidad, que son de tamaño pequeño y por lo tanto sólo pueden ser abiertos mediante la aplicación de esta técnica. Si bien existen clastos de mayores dimensiones, en ellos la calidad para la talla es netamente inferior, dado que presentan innumerables fisuras y planos de fragilidad internos que prácticamente impiden obtener buenos soportes.

Alrededor de un 35\% de las lascas no muestran tales rasgos en su porción conservada y por lo tanto podrían haber sido obtenidas tanto por técnica bipolar como por percusión a mano alzada, razón por la cual fueron contabilizadas por separado. Sin embargo, por las características de los nódulos de materia prima disponibles naturalmente, es altamente probable que buena parte de ellas corresponda también a la técnica bipolar.

La tercera cadena operativa es la reducción bifacial, que aparece representada exclusivamente por una punta de proyectil, no confeccionada en el sitio, ya que no se hallaron productos de reducción bifacial en esa materia prima, ni tampoco microlascas de terminación.

La cuarta, es la de confección de instrumentos sobre guijarros por piqueteamiento o pulimentación, para los cuales tampoco existen en el sitio restos de formatización ni herramientas para su confección, por lo que también se considera que han sido aportados ya terminados.

\subsection{Caracterización de los raspadores}

En cuanto a la caracterización morfotécnica de los diferentes grupos de instrumentos presentes, se constató que a su amplio predominio en el conjunto, los raspadores agregan como característica una gran homogeneidad en cuanto a rasgos tecnomorfológicos. Considerando los criterios dimensiones, soporte, morfología de la cara dorsal y extensión del retoque, los grupos mayoritariamente representados son los raspadores no estandarizados y los raspadores chicos, estos últimos con una subdivisión, los microlíticos. Uno de los datos relevantes de este análisis es que en la mayoría de los casos (75,7\%), los largos máximos de los raspadores están comprendidos entre 1,5 y $2,5 \mathrm{~cm}$. Como se mencionó al comienzo, la subdivisión de los raspadores microlíticos se hace normalmente a partir de un límite arbitrario fijado en los $2 \mathrm{~cm}$. Sin embargo, en función de estos resultados, y considerando que ninguno de los otros criterios de análisis parece guardar relación con uno u otro grupo morfométrico, es posible que la misma deba ser reconsiderada, al menos para el caso de los otros conjuntos de la región.

\subsection{Los usos de los instrumentos}

El análisis funcional de los instrumentos pone en evidencia una alta integridad funcional para los raspadores, independientemente de la subdivisión morfotécnica a la que pertenezcan. Tales instrumentos fueron principalmente utilizados para el raspado de cueros, con modo de uso transversal. Por las características de los rastros de uso observados (micropulidos y rasgos microtopográficos asociados) es probable que se trate de pieles de mamíferos continentales (guanaco, zorro, etc.) y no de mamíferos marinos. La actividad inferida es el raspado/adelgazamiento de pieles en estado seco, bajo presión.

En cuanto a las raederas, su baja representación y el alto grado de incidencia de alteraciones depositacionales impiden formular conclusiones generales. En cuanto a la cinemática del trabajo, sólo se determinaron acciones longitudinales. Con respecto a los materiales trabajados, los resultados sugieren mayor versatilidad en su empleo, ya que al menos se identificó un caso de trabajo sobre madera fresca. En los casos en los que no resulta posible efectuar una determinación segura debido a las alteraciones postdepositacionales, podría tratarse de procesamiento de recursos animales blandos o medios (faenamiento, corte de pieles, etc.) o eventualmente del trabajo de madera de poca duración, rastros que quedarían enmascarados por la abrasión.

En el transcurso del análisis no fue posible detectar indicios claros con respecto al enmangamiento de los instrumentos. Si bien el mismo no resulta indispensable en el caso de las raederas, en el de los raspadores sus pequeñas dimensiones dificultan la prehensión manual. El modo de utilización inferido a partir de la distribución de los rastros de uso, profundos sobre cara ventral, con abundantes estrías oblicuas/perpendiculares al filo, indica que fueron usados en un movimiento con cara ventral como cara de contacto y ángulo intermedio a alto. 
Tal modo de uso requeriría de un enmangue de tipo terminal axial (cf. Stordeur, 1987), tal como los que se conocen en los contextos yámanas para los cuchillos de valva. Además, el proceso de reactivación con este tipo de enmangue resulta sumamente fácil, ya que puede efectuarse directamente con el instrumento lítico enmangado, al contrario de lo que sucede con cualquiera de los otros modelos, en los cuales rápidamente se hace necesario retirar la pieza lítica del mango para reactivarla o reemplazarla.

El empleo de un dispositivo de enmangue de este tipo coincidiría con la observación sobre la intensidad de reactivación de los raspadores, que a priori podría resultar llamativa ya que como dijimos, la vida útil de los instrumentos es alta. En nuestras pruebas experimentales, si bien los tiempos de uso de los instrumentos no superaron los 60 minutos, los filos seguían siendo efectivos luego de transcurrido ese lapso. La intensidad de reactivación detectada coincide entonces con la utilización inferida a partir de los rastros de uso, sobre cueros y con bastante presión, y sugiere además tiempos de uso bastante largos.

\subsection{Participación de los instrumentos} en otras cadenas operativas

Los rastros de uso detectados en los filos de los instrumentos indican su participación en otras cadenas operativas de procesamiento de recursos de origen vegetal y animal.

El procesamiento de vegetales ha sido demostrado para al menos una de las raederas (corte, no es posible aún discriminar entre madera y corteza) y uno de los raspadores (probablemente madera). Tan escasa representación resulta llamativa, ya que los recursos vegetales participan además en otras cadenas operativas, tal como el procesamiento de cueros (mangos para raspadores, marcos para secado de pieles, etc.).

Con respecto al procesamiento de recursos animales, cabe mencionar la escasez de instrumentos utilizados para trabajar hueso, cuando se han descubierto instrumentos óseos en el registro. En el caso de los punzones, confeccionados básicamente por pulimentación, puede considerarse que se trata de instrumental conservado, o al contrario que lo conservado es el alisador que se utiliza en su confección. También resulta llamativa la escasez de filos para corte de material blando de origen animal (piel fresca, carne), tarea que como se dijo podría haber sido realizada por las raederas usadas en acciones de corte.

En relación al procesamiento de pieles, se ha demostrado el uso intensivo de los raspadores para trabajo de cueros.

\section{CONCLUSIÓN}

En función de los resultados que acabamos de puntualizar, consideramos que la singularidad del conjunto del Cuarto Componente y su baja diversidad artefactual pueden ser explicadas como consecuencia de la realización de una actividad predominante: el trabajo de cueros. Para ello se utilizaron intensivamente pequeños raspadores altamente estandarizados desde el punto de vista morfológico, para cuya confección se adoptaron estrategias específicas en cuanto a la selección de la materia prima y las técnicas de producción de formas base.

Con respecto a ellas, nos interesa resaltar dos aspectos importantes. El primero se refiere a la alta concentración espacial de los raspadores en el sitio. En función de los resultados obtenidos de este análisis, y considerando que resulta poco probable que se trate de un lugar de descarte preferencial de raspadores, proponemos que su alta concentración espacial en realidad estaría indicando la concentración espacial de actividades vinculadas con el procesamiento de pieles o cueros. En tiempos históricos, el procesamiento de pieles entre los canoeros magallánico-fueguinos incluía la extracción, tensado y secado, raspado para limpieza final y adelgazamiento, sobado manual y finalmente uso (directo o como materia prima para la confección de variados elementos). Con respecto a la extracción de las pieles, la concentración aludida no parece guardar relación con los restos faunísticos recuperados en el sitio, lo que podría indicar que el ingreso de las pieles se produjo sin las partes esqueletarias. En cuanto al tensado y secado, las escasas referencias de las fuentes etnográficas e históricas para la última época mencionan estructuras de marco de madera, colocadas directamente al sol o sobre amplios fogones (en época húmeda o lluviosa). No hay menciones sobre el raspado, pero nuestras observaciones sugieren que en tales condiciones de tratamiento de las pieles, éste no 
requiere forzosamente ser muy intenso, salvo en los casos particulares de tratamiento de cueros secos para confección de recipientes, correas, etc. Por lo tanto esta concentración podría indicar el lugar destinado a ambos pasos (secado y raspado).

El segundo se refiere a la relación entre la materia prima seleccionada, las categorías morfotécnicas de los instrumentos y su utilización. Como se mencionó anteriormente, la relación entre materia prima y morfología parece ser directa en el caso de las raederas. Se utilizaron filos largos con ángulos intermedios y rectos, en acciones longitudinales, y para ellos resulta muy difícil obtener soportes con dimensiones adecuadas, o filos de sección medianamente rectilínea, en el cuarzo local. En el caso de los raspadores de cuarzo, si se consideran exclusivamente las características de las formas base, habría sido posible obtener soportes con dimensiones similares a los usados, utilizando otras materias primas; sin embargo en ellas resulta difícil lograr módulos de espesor como los registrados en el conjunto. Al contrario, si se considera el uso al que fueron destinados, de raspado de cueros bajo presión, resulta más efectivo y duradero un filo de cuarzo que uno de riolita, que tiene tendencia al desgranamiento. En situación intermedia en cuanto a la resistencia de los filos se encuentra la cinerita, pero se trata de un material relativamente escaso, en comparación con la riolita.

En función de estas observaciones, si el criterio para la selección de la materia prima para los raspadores utilizados para trabajar cueros fuese exclusivamente funcional, entonces debería esperarse en general que los raspadores de la región del Canal Beagle fuesen de cuarzo, lo cual hasta ahora sólo se ha constatado en el Cuarto Componente de Túnel I (si bien existen otros conjuntos en los que predominan los raspadores chicos, por ejemplo en Shamakush I y Lanashuaia, en ellos la materia prima predominante no es el cuarzo). Si al contrario consideramos la técnica para la obtención de soportes de cuarzo adecuados para la confección de raspadores, el empleo de la técnica de apertura bipolar no resulta particularmente económico, ya que sus resultados son relativamente aleatorios y producen una altísima cantidad de desperdicio. Alternativamente, la cinerita se revela como un material adecuado en el aspecto funcional, pero su obtención es difícil, ya que se trata de un material relativamente escaso en las inmediaciones del sitio, y porque resulta prácticamente imposible diferenciar los nódulos de cinerita de los de riolita simplemente por el aspecto exterior. Para localizarlos, es necesario realizar una talla de prueba. En consecuencia, consideramos que en el caso del IV Componente se priorizó una estrategia de facilidad de identificación, selección y transporte de la materia prima (guijarros de cuarzo), frente a una estrategia más segura en el aspecto tecnológico pero que insume más tiempo de localización (cinerita). Al tratarse de un caso hasta ahora único en el registro arqueológico del Canal Beagle, tal estrategia podría estar más relacionada con la solución de un problema imprevisto que con la realización de una actividad programada.

Desde este punto de vista, la selección de guijarros de cuarzo constituyó una alternativa altamente eficiente, tanto por el bajo costo de provisión de materia prima adecuada para las técnicas de confección implementadas, como por la efectividad de los filos para la tarea a la que estaban destinados.

\section{BIBLIOGRAFÍA}

ÁLVAREZ, M. 2003. Organización tecnológica en el Canal Beagle. El caso de Túnel I (Tierra del Fuego, Argentina). Tesis de Doctorado, UBA.

ÁlVAREZ, M; LASA, A. y MANSUR, M. E. 2000. La explotación de recursos naturales perecederos: análisis funcional de los raspadores de la costa norte del canal Beagle. Relaciones de la Sociedad Argentina de Antropología 25: 275-295.

BINFORD, L. 1979. Organization and formation proceses: Looking at curated technologies. Journal of Anthropological Research 35 (3): 255-273.

CLEMENTE, I. y TERRADAS, X. 1993. Matières premières et fonctions: l'exemple de l'outillage lithique des Yámanas (Terre de Feu). En: Traces et fonction: les gestes retrouvés. Ed. ERAUL vol 59, pp. 513-521.

CLEMENTE, I.; MANSUR, M. E.; TERRADAS, X. y VILA MITJA, A. 1996. Al César lo que es del César: Los "instrumentos" líticos como instrumentos de trabajo. En: Arqueología. Solo Patagonia. Coord. Julieta Gómez Otero. Publ. CENPAT, pp. 319-332, Puerto Madryn.

LANATA, J. L. 2000. ¿Diversidad artefactual o complejidad? El caso de los cazadores-recolectores fueguinos. En: Anais do IX Congresso da Sociedade de Arqueologia Brasileira.

LEROI-GOURHAN, A. 1964. Le Geste et la Parole I. Technique et langage. Albin Michel, Paris. 323 p., 105 fig.

LEROI-GOURHAN, A. 1971. L'Homme et la Matière. Evolution et Techniques I. et langage. Albin Michel, Paris. 2a. éd., 367 p., fig.

MANSUR, M. E. 1986. Microscopie du matériel lithique préhistorique: Traces d'utilisation, altérations naturelles, 
accidentelles et technologiques. Cahiers du Quaternaire 9, Éd. C.N.R.S., 286 p. Bordeaux.

MANSUR, M. E. 1997. Functional analysis of polished stonetools: some considerations about the nature of polishing. En: Siliceous rocks and Culture, M.A. Bustillo y A. Ramos Millán (Eds.), pp. 465-486. Universidad de Granada.

MANSUR, M. E. 1999. Análisis funcional de instrumental lítico: problemas de formación y deformación de rastros de uso. En: Actas del XII Congreso Nacional de Arqueología Argentina, t. 1. pp. 355-366. La Plata.

MANSUR, M. E. y CLEMENTE, I. 2002. ¿Tecnologías invisibles? Confección, uso y conservación de instrumentos de valva en Tierra del Fuego. En prensa en Actas y Trabajos del XIV Congreso Nacional de Arqueología Argentina, Rosario.

MANSUR, M.E. y LASA, A. 2005. Raw materials, manufacture and use: a case study from Túnel I site (Tierra del Fuego, Argentina). Comunicación en el World Congress Prehistoric Technology, 40 years later: Functional Studies and the Russian Legacy. Verona, Italia.

MANSUR, M. E.; LASA, A. y VÁZQUEZ, M. 2004. Investigaciones arqueológicas en Punta Bustamante, Prov. de Santa Cruz: el sitio RD01BK. En: Contra viento y Marea. Arqueología de Patagonia. INAPL, Buenos Aires. Pp. 755-775.

MANSUR, M. E. y VILA MITJA, A. 1993. Lanalyse du matériel lithique dans la caractérisation archéologique d'une unité sociale. En: Traces et fonction: les gestes retrouvés. Ed. ERAUL vol 59, pp. 501-512.
OLIVERO, E. y MARTINIONI, D. 2001. A Review of the Geology of the Argentinian Fuegian Andes. En: Mesozoic Paleontology and Stratigraphy of South America and the South Atlantic, P. Bengtson (ed.), Journal of South American Earth Sciences, Vol. 14 (2): 175-188.

ORQUERA, L. y PIANA, E. 1986. Normas de descripción de objetos arqueológicos de piedra tallada. CADIC Centro Austral de Investigaciones Científicas, Contribución Científica № 1, 108 p. Ushuaia.

ORQUERA, L. y PIANA, E. 1988. Composición tipológica y datos tecnomorfológicos y tecnofuncionales de los distintos conjuntos arqueológicos del sitio Túnel I (Tierra del Fuego). Relaciones de la Sociedad Argentina de Antropología, T.XVII/1: 201-239.

ORQUERA, L. y PIANA, E. 1999a. Arqueología de la región del canal Beagle (Tierra del Fuego, Argentina). Sociedad Argentina de Antropología. 146p.

ORQUERA, L. y PIANA, E. 1999b. La vida material y social de los yámana. Ed. Eudeba. 567 p. Buenos Aires.

PIGEOT, N. 2003. L'Economie de la taille de la pierre. En: Cazadores-Recolectores de Ponsonby (Patagonia Austral) y su paleoambiente desde VI al III milenio A.C. D. Legoupil. Magallania Vol. 31, número especial: 117-164.

SHANNON, C. E. y WEAVER, W. 1949. The mathematical Theory of Communication. The University of Illinois Press, Urbana.

STORDEUR, D. 1987. Manches et emmanchements préhistoriques: quelques propositions préliminaires. En: La main et l'Outil. Manches et Emmanchements préhistoriques. Maison de l'Orient, Lyon. 
